\title{
البهمث 1لثُالث:
}

\section{أثر استخدام برناهمج مقتزح في تنمية الذكاء الانفعالي لدى طلاب كلية التزبية بالمنيا}

\section{: إعــــــ}

د. أسماء محمد عبد الحميد محمد

مدرس علم النفس التربوي بكلية التربية جامعة المنيا 


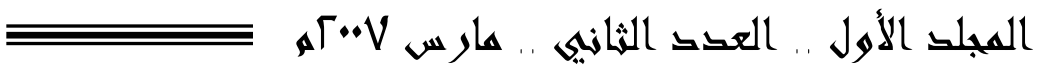

\section{" أثر استخدام برناهج هقترح في تنسية الذكاء الانفعالي لدى طلاب كلية}

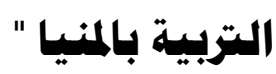

د. . أسماء محمد عبل الحمبا محمد

\section{كلية التربية جامعة المنيا}

\section{هقدمة ومشكلة الدراسة :}

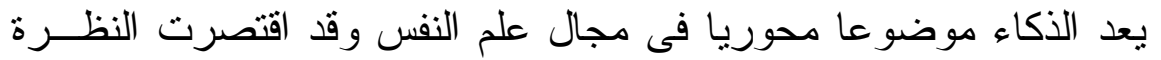

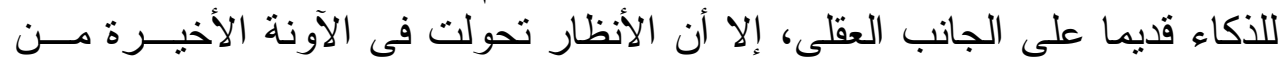

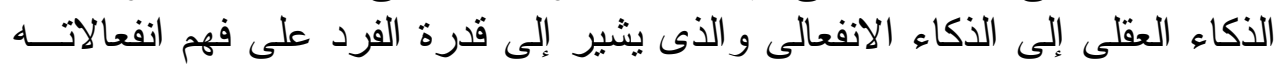

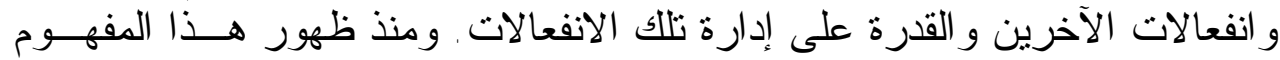

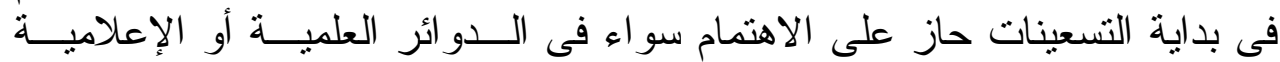

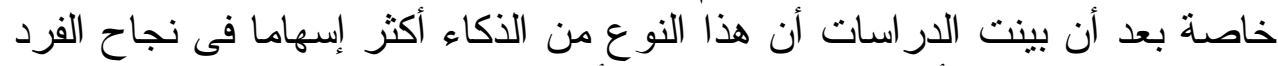

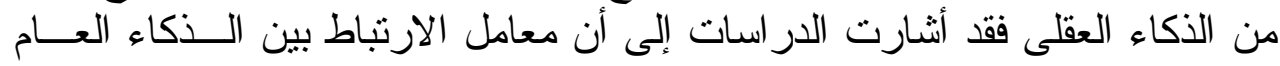

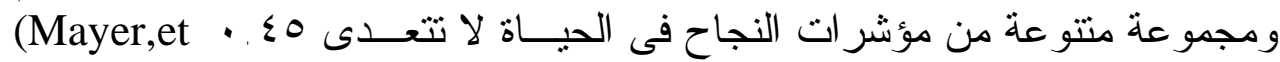

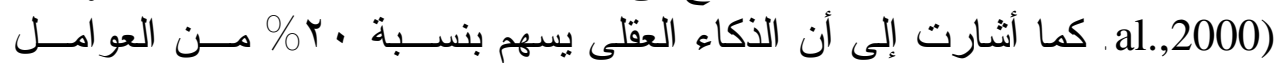

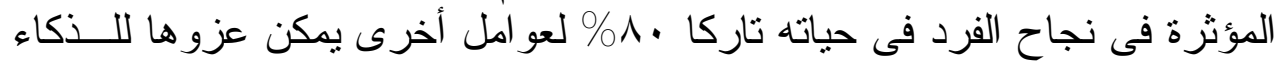
الانفعالى (Goleman, 1995; Mayer\&Salovey,1997).

ورغم أن الذكاء الانفعالى مفهوم حديث إلا أن البدايات الأولى لهذا المفهــوم

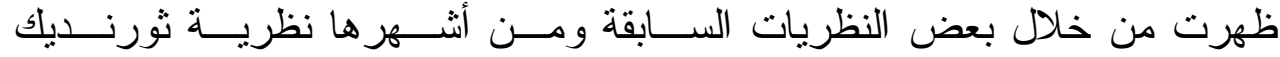
(Throndike,1920)

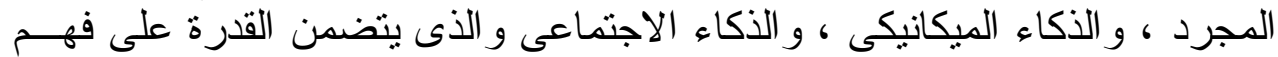

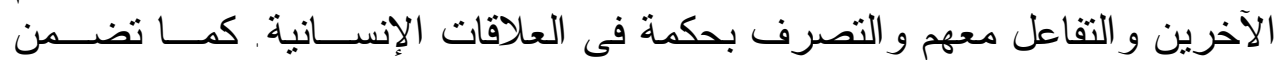

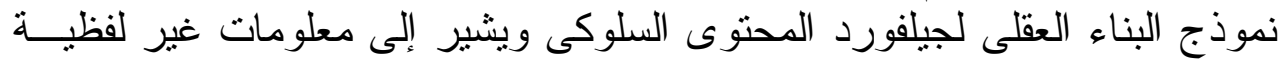

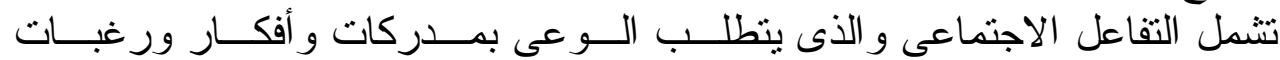

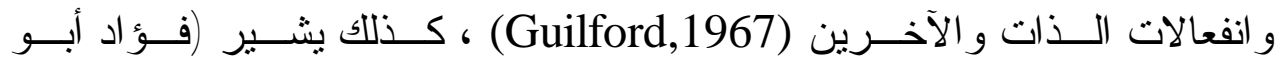

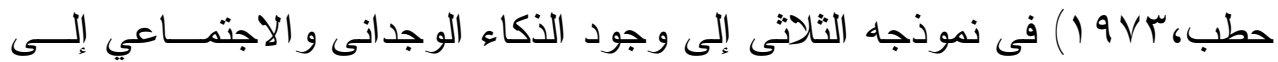

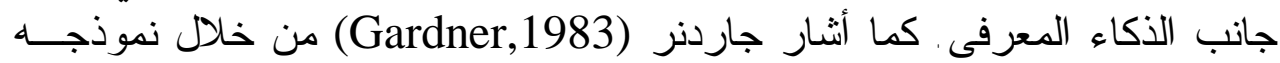

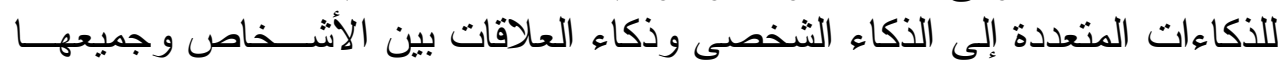
مفاهيم متضمنة فى الذكاء الانفعالى . إلا أن مفهوم الذكاء الأنفعالى تم تقديمه بشكله الحالى بو اسطة (Salovey\&Mayer,1990) و اللذان يعرفان الذكاء الانفعالى بأنه

\section{I. $r$}

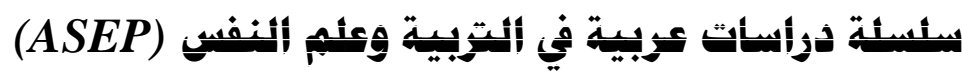




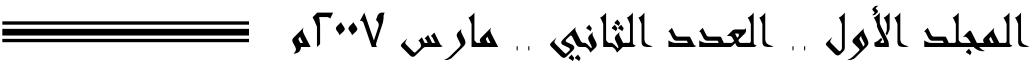

القدرة على إدر الك الانفعالات و إنتاجها لتيسير عملية التفكير ، و القدرة على استخدام

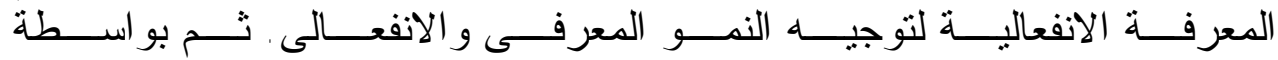
(Goleman,1995)

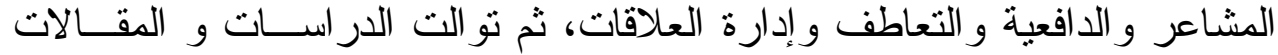

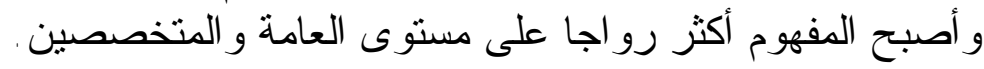

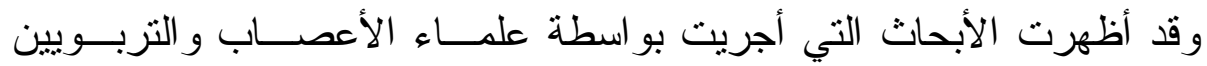
ارتباطا قويا بين الانفعالات و ألتفكير ، وبالتالى كلما تحسن الجانب الانب الانفعالي للمتعلم

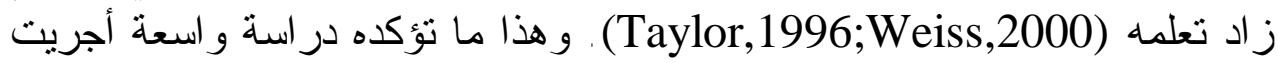

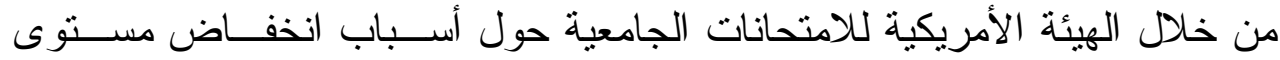

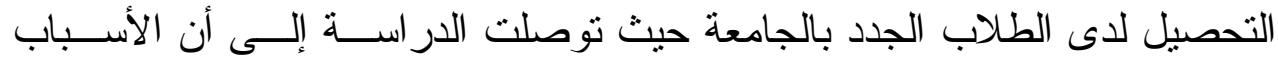

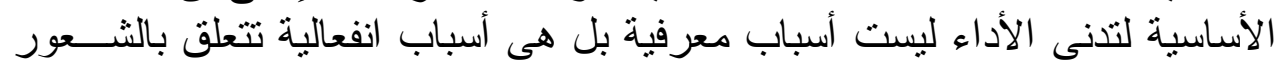

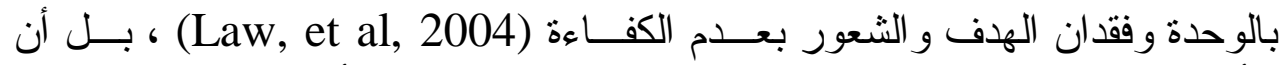

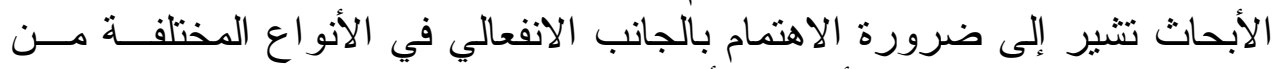

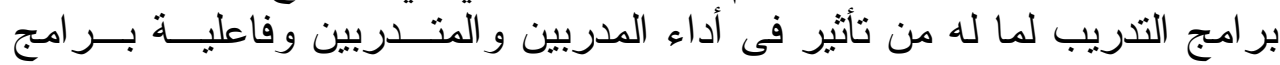

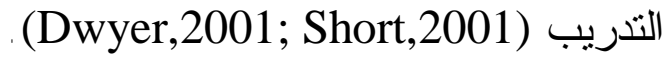

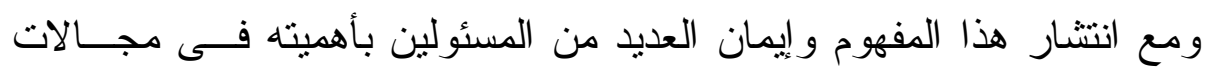

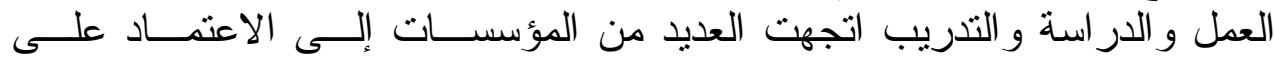

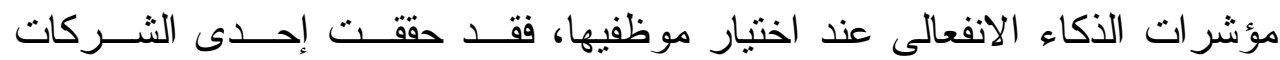

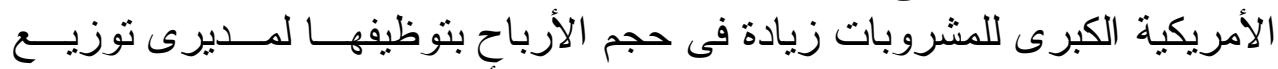

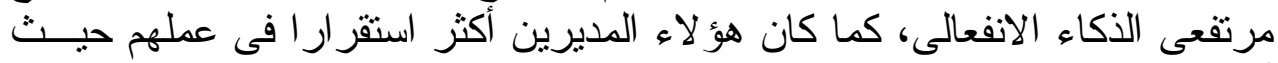

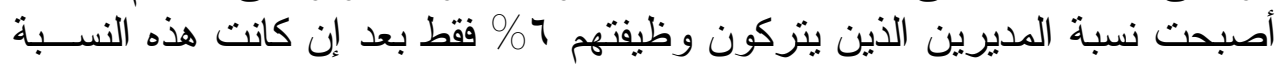

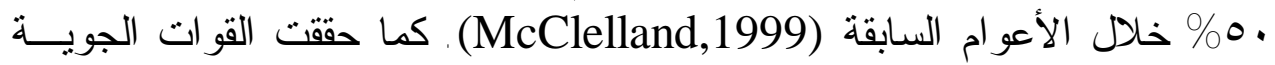

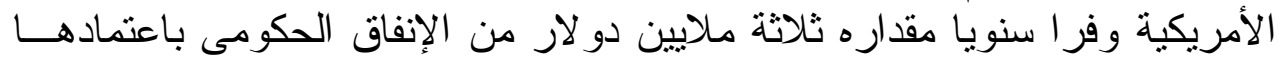

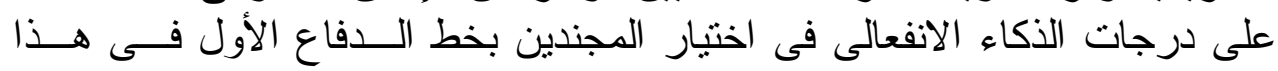

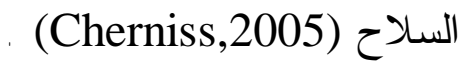

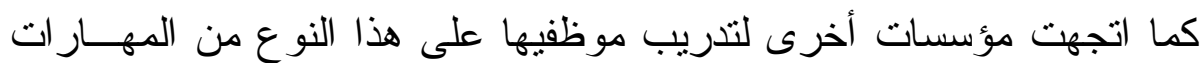

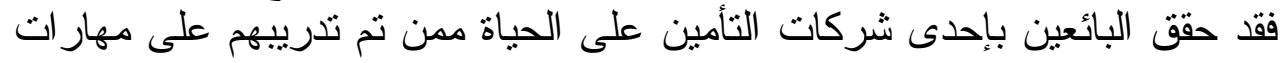

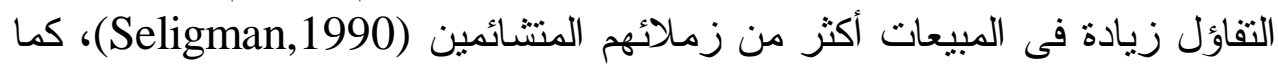

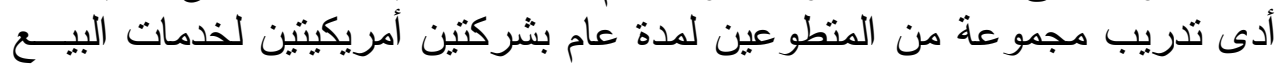

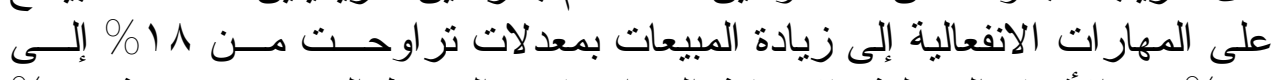

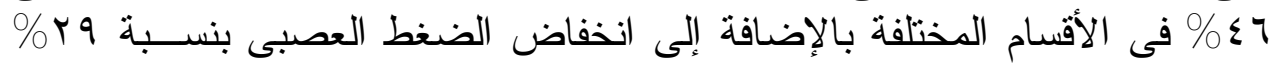

\section{$1 \cdot \varepsilon$}

سلسلة دوأسات عربية في الثتبية وعنم النففي (ASEP) 
ב"

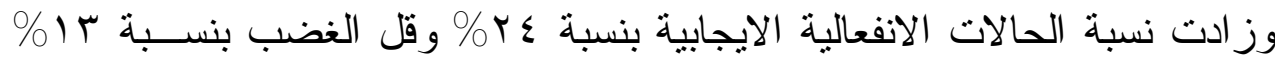
كما تحسنت الحالة الجسدية لدى المتدربين بصورة دالة (Luskin et al.,2005). ومع تأكيد العديد مــن البــاحثين علــى قابليــة الــذكاء الانفعــالى للتتميــة

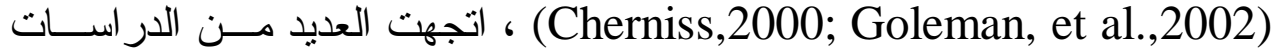

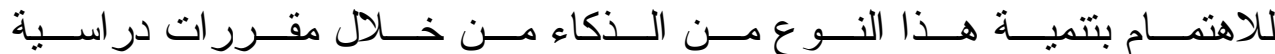
(Aeger,2002;Clark,et al.,2003; DuPont,1998; Fischer, 2003; أو من خلال بر امج تدريبية معدة لهذا الغرض Richardson\& Evans,1997) (Boyatizis et al,1995; Boyatzis et al, 1996; Boyatzis et al, in press; Bruno, et al.,2002; Gore, 2002; Curtis, 2000; Luskin et al., 2005; Seligman,1990; Law, et al,2004)

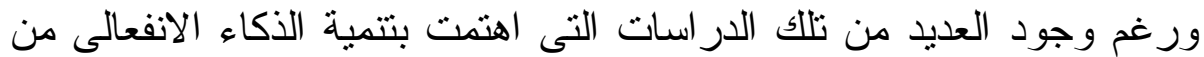

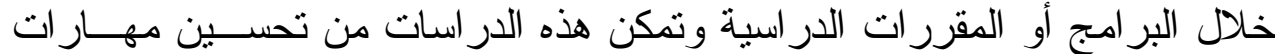

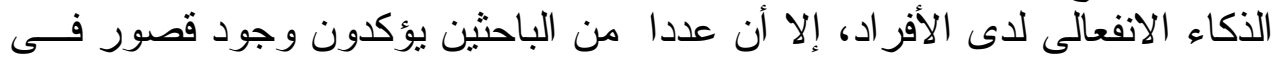

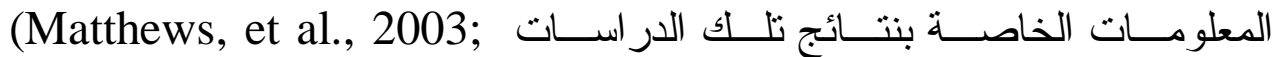
Mayer\& Cobb, 2000; Wong, et al. 2006; Zeidner, et al., 2002) مما يشكك فى فاعلية البر امج المستخدمة خلال تلك الدر اسات، ويرجـع البــاحثين جانبا أساسيا من هذا القصور إلى عدم اعتمادها على نموذج محدد في تتمية الذكاء الماء

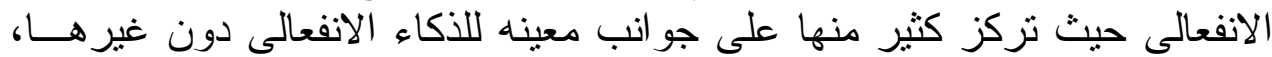

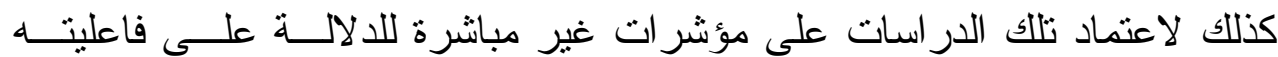
بر امجها، أو استخدامها لمقاييس تفتقر إلى الخصائس التص السيكومترية المناسبة لقياس

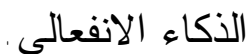

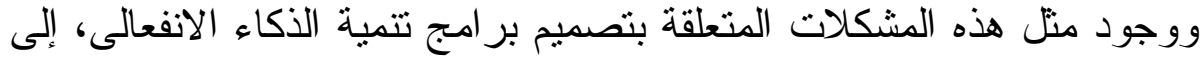

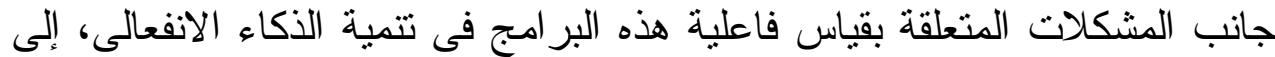

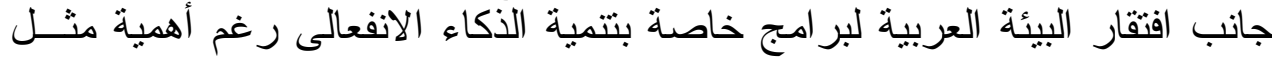

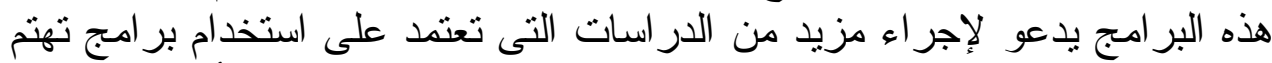

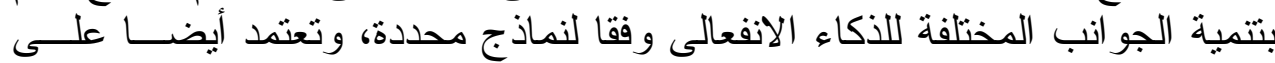

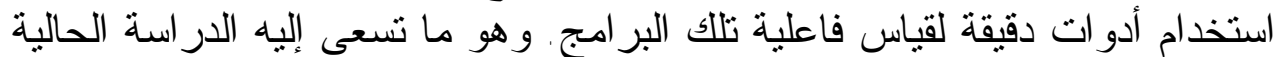

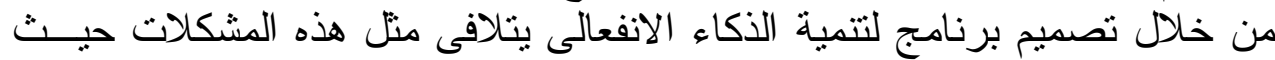

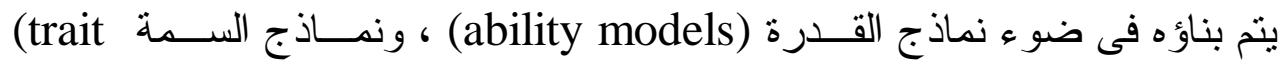
models)

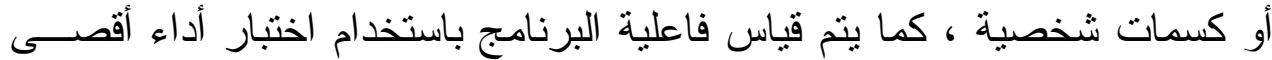

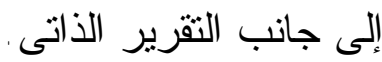


تتلخص مشكلة الدر اسة الحالية فى أنه رغم وجود العديد من تلأك الدر اســات

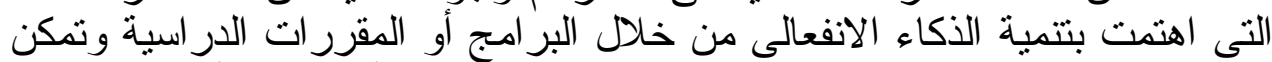

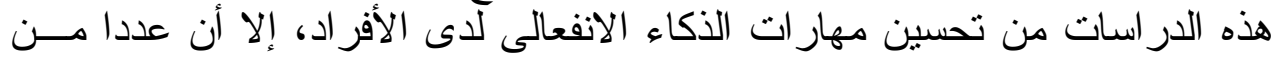

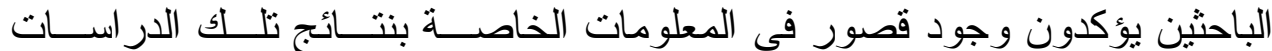
(Matthews, et al., 2003; Mayer\& Cobb, 2000; Wong, et al. 2006; Zeidner, et al., 2002)

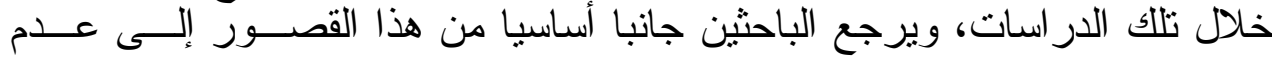

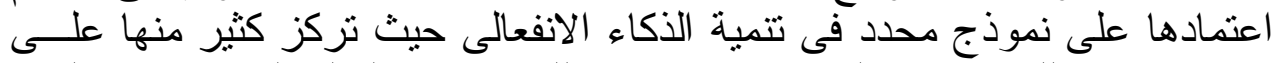

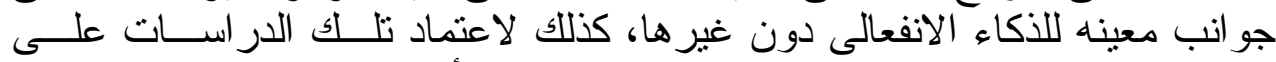

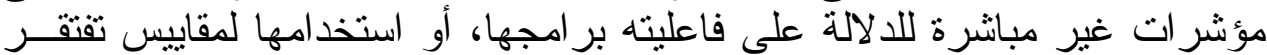
إلى الخصائص السيكومترية المناسبة لقياس الذكاء الانفعالى.

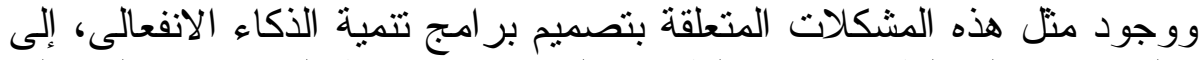

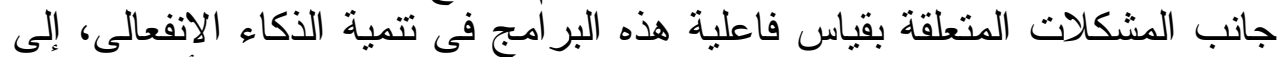

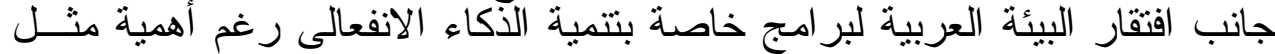

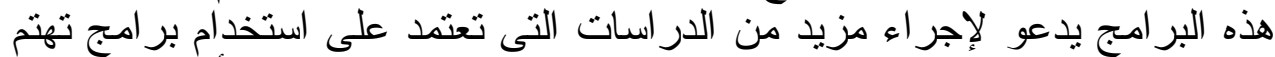

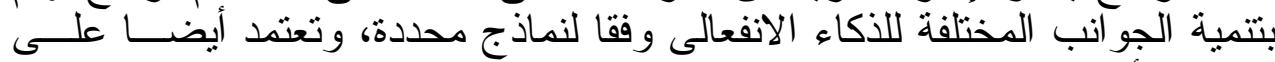

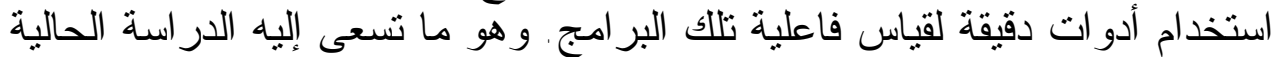

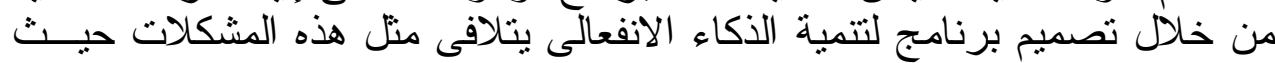

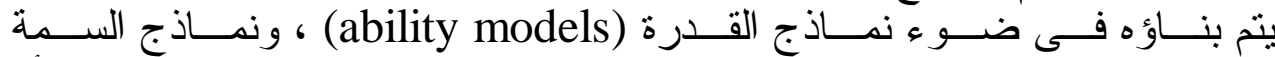

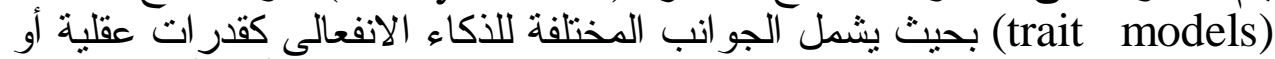
كسمات شخصية، كما يتم قياس فاعلية البرنامج باستخدام اختبار أداء أقصى إلفى إلـى التى جانب التقرير الذاتى .

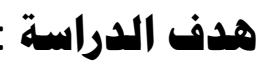

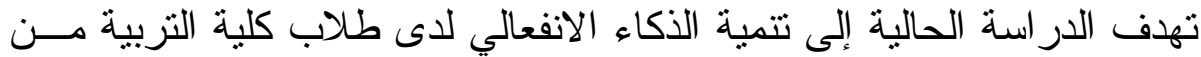

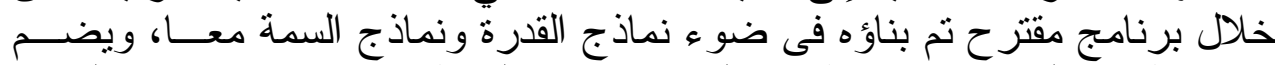

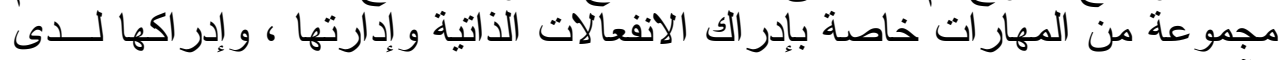
الآخرين و إدارتها

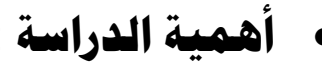

للار آسة الحالية أهمية تتعلق بالجانب الأكاديمى و النفسى و المهنى

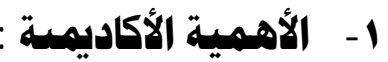

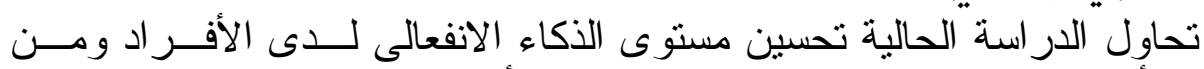

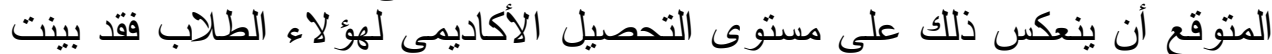

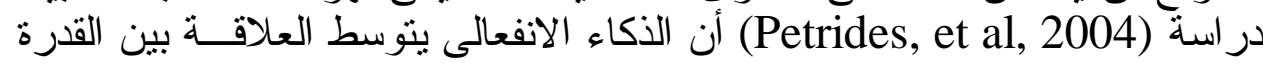




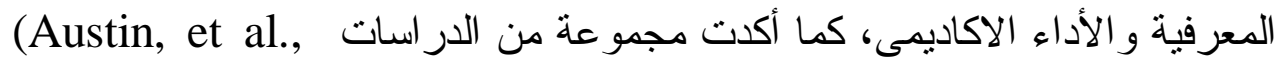
2005; Fannin, 2002; Jaeger, 2003; Kapp,2000; Mayer\& Salovey, 20197; Parker, et al., 2004a,b; Schutte, et al., 1998)

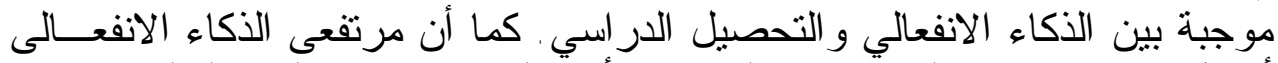

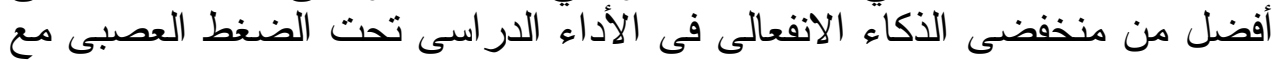

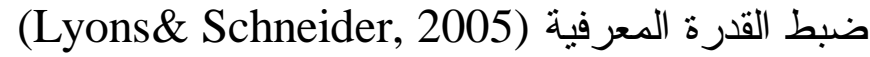

يؤدى الارتقاء بمستوى الذكاء الانفعالى لدى الأفر اد إلى تحسـين حـــالاتهم

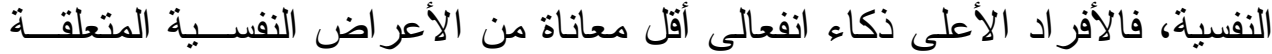

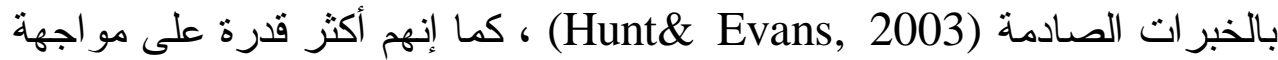

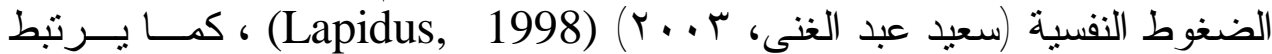

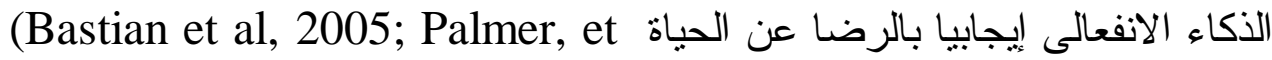
(Engelberg \& Sjoberg, 2004) و إيجابيا بالتو افق الاجتمــاعى al 2002)

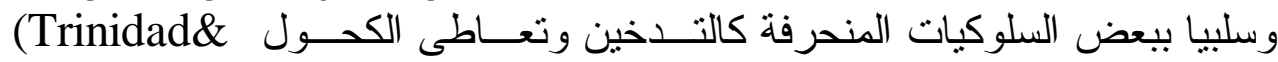
(Johnson, 2002 ، و القلق (Bastian, et al, 2005) ، و اضطر ابات الثخصية

(Leible\& Snell, 2004)

الارتقاء بمستوى الأكاء الانفعالى لاءى طلاب كلية التربية (معلمى المســتقبل)

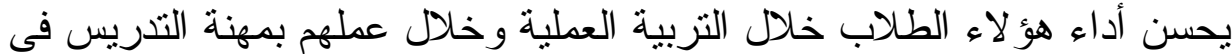

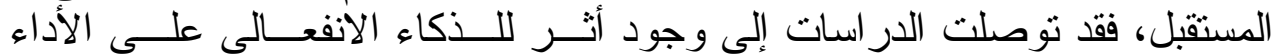

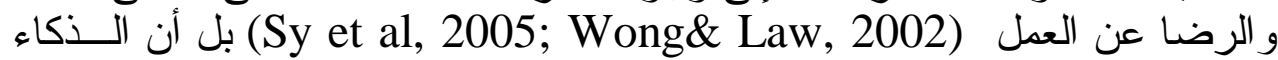

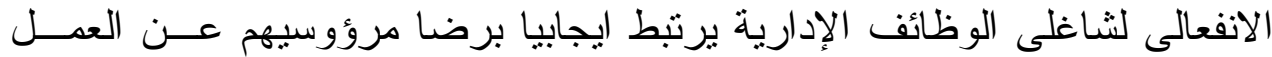

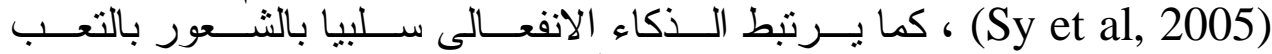

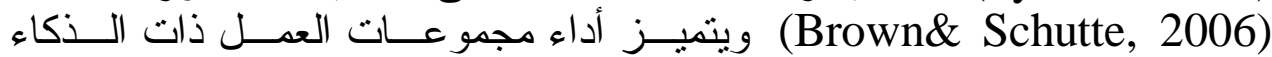

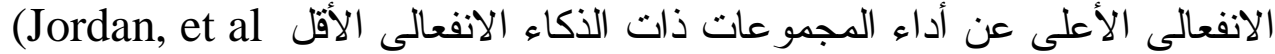

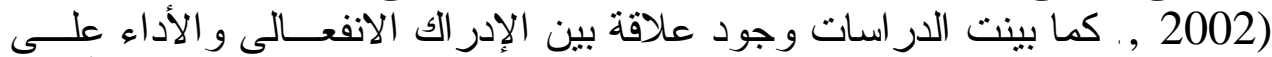

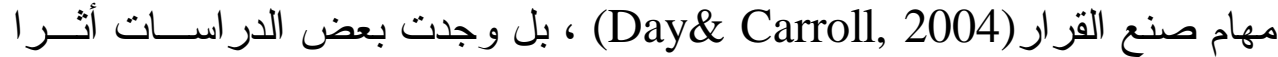

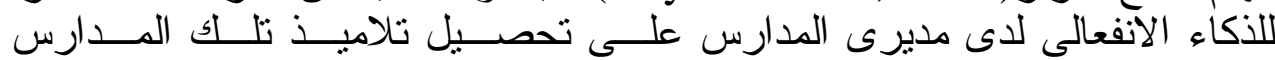
.(Bardach,2008)

\section{مصالمات الدراسة}

Emotional Intelligence : الذكاء الانفعالى تأخذ الدر اسة الحالية بتعريف Mayer, et al.,2002a) للذكاء الانفعالى بأنه

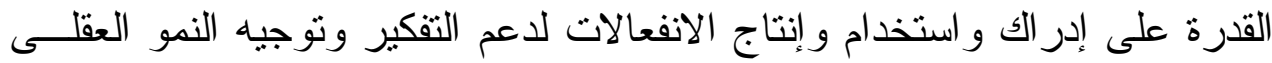

\section{$1 \cdot V$}


ב年

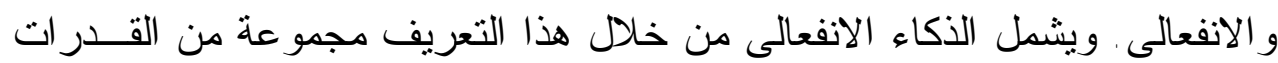

7 إدر الك الانفعالات Perceiving Emotions : ويشير إلى قدرة الفرد على الإنى

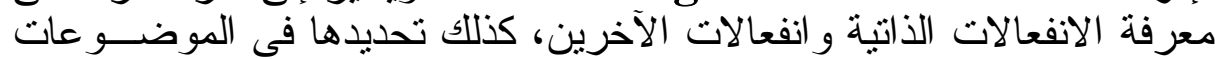

و الرسوم و الموسيقى و غير ها من المثير ات .

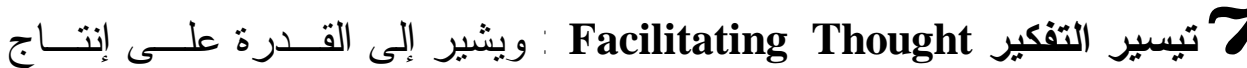

و استخدام المشاعر وتوظيفها لتيسير النمو المعرفى وحل المشكلات.

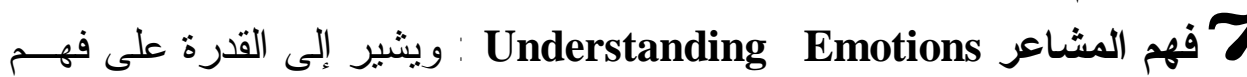

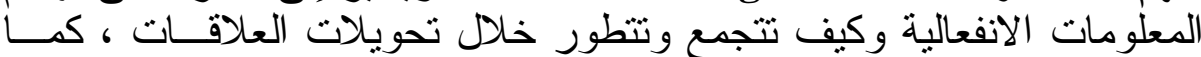

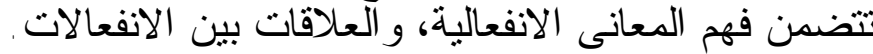

7 إدارة المشاعر Managing Emotions : يثير إلى قدرة الفرد على تعــديل

انفعالاته و انفعالات المثاعر الآخرين

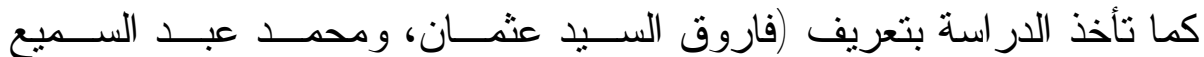

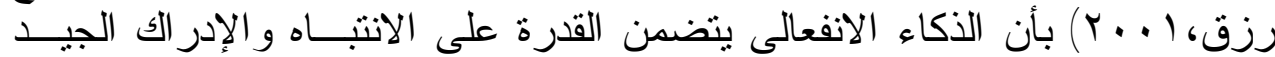

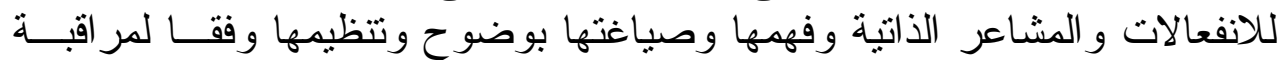

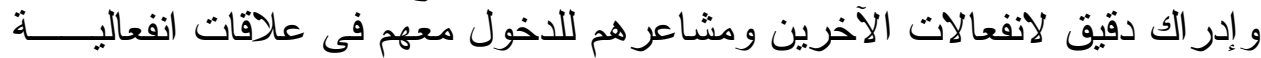

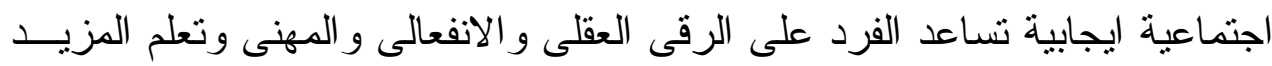

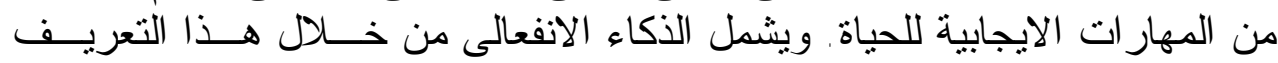

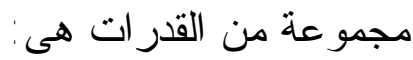

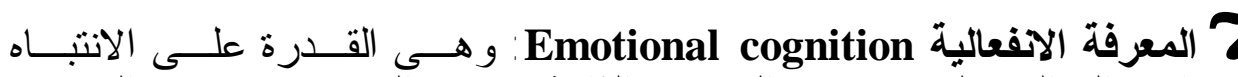

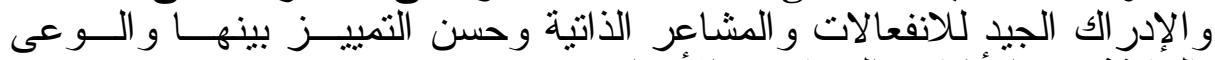
بالعلاقة بين الأفكار و المشاعر و الأحداث.

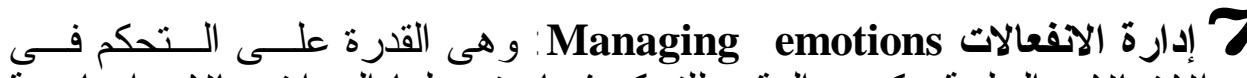

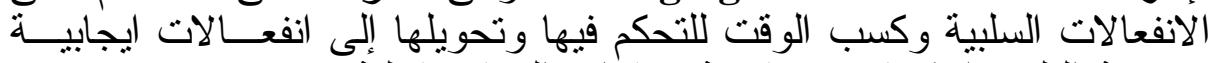
وهزيمة القلق و ألاكتئاب وكماب وممارسة مهار ات الحياة بفاعلية.

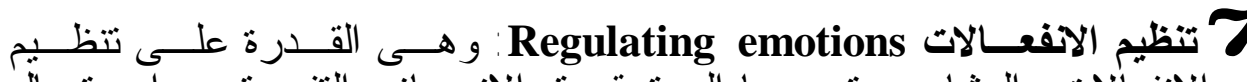

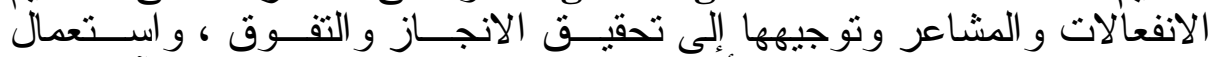

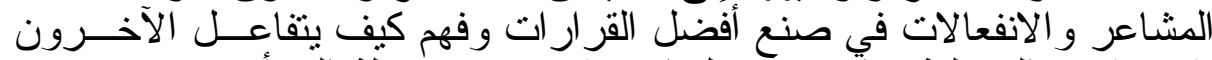

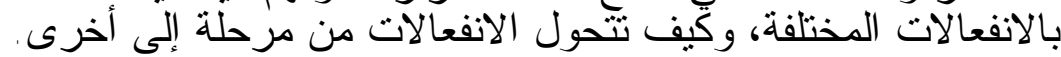

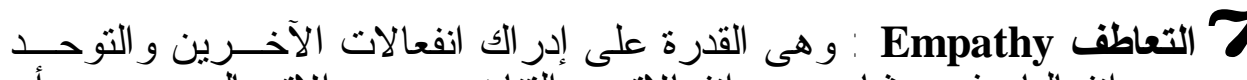

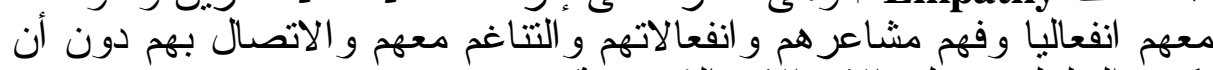
يكون السلوك محمل بالانفعالات الشخصية.

\section{$1 \cdot 1$}

سئسية دوأسأت عربية في التزبية وعنم النففي (ASEP) 


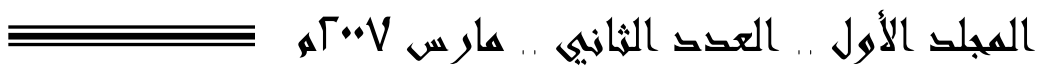

7 التواصل Communication: وهى القدرة على التأثير الإيجابي في الآخرين

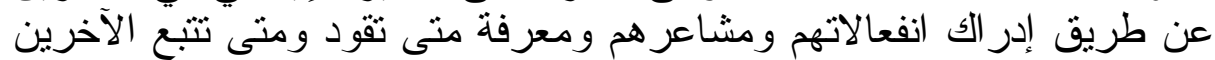
وتساندهم و التصرف الترن معهم بطريقة لائقة.

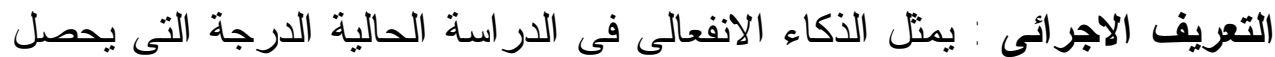

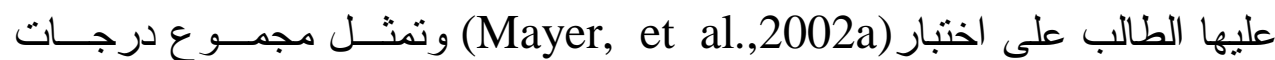
الأبعاد الأربع : إدر الك الانفعالات، وتيسير التفكير، وفهم المشاعر ، إدارة المشاعر مجاعر

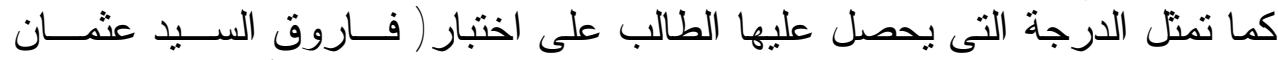

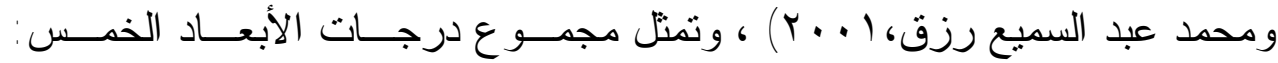

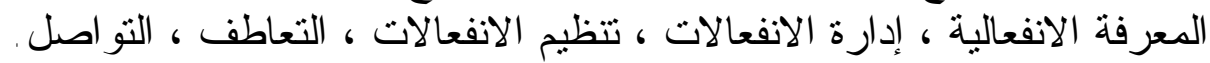

\section{• الإطار النظرى والدراسات السابقة :}

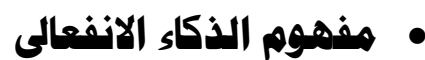

بعد اقتصار مفهوم الذكاء لاعى العديد من الباحثين ولفترة زمنية طويلة علـى

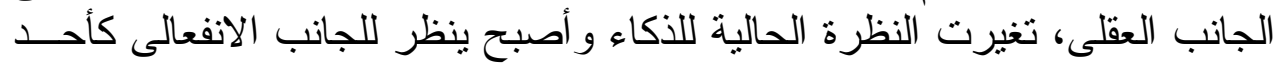

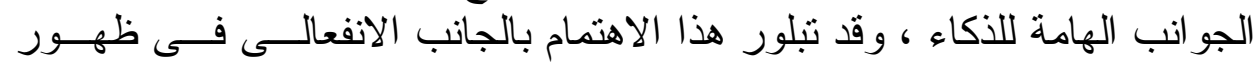

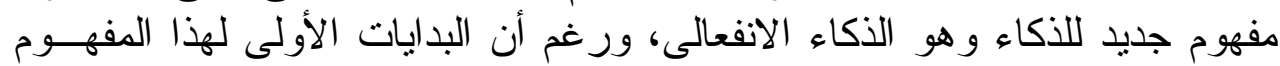

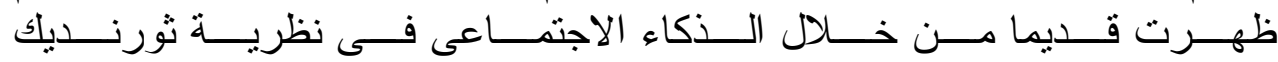

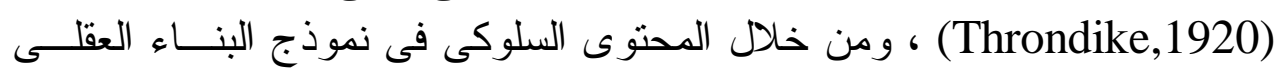

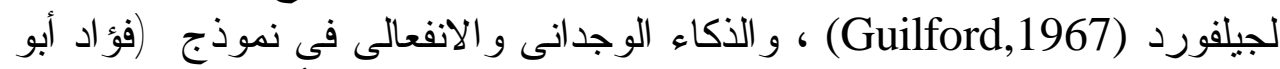

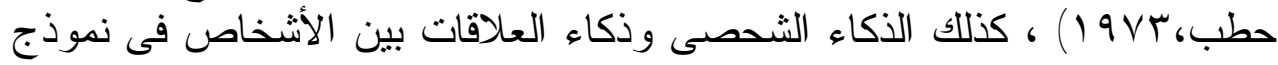

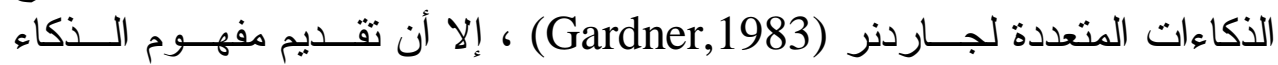

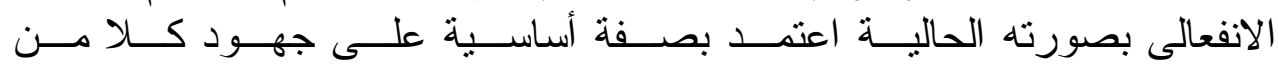

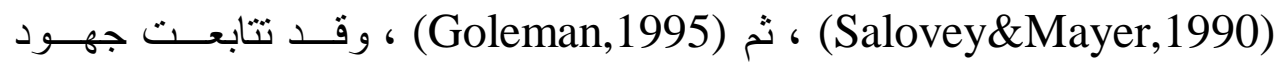
الباحثين منذ ذلك الحين فى محاولة لتتاول الجوانب المختلفة لهذا المفهوم ومحاولة

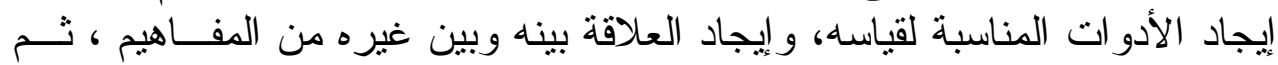

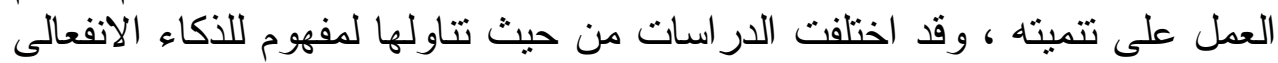
إلا أنها تتدر ج تحت فئنتين رئيستين (Petrides\&Furnham,2000,2001) الفئـة فئة

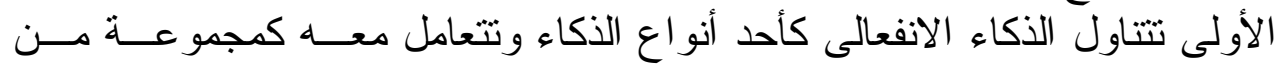

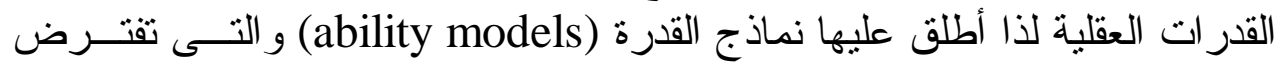
أن الذكاء الانفعالى أحد أنواع الذكاء وذلإنك من خلاجل مقابلته لمجموعة من المعايير

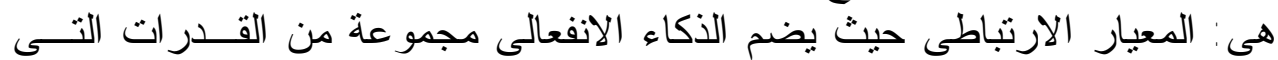

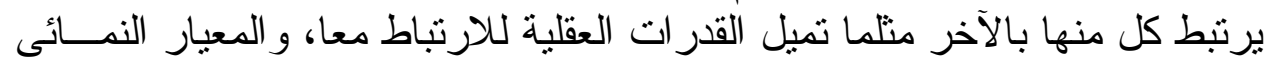

\section{9}

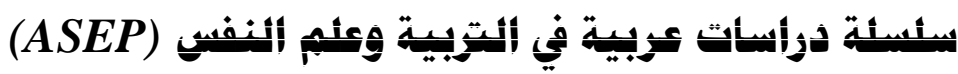




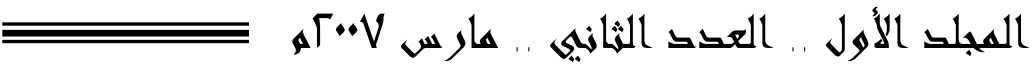

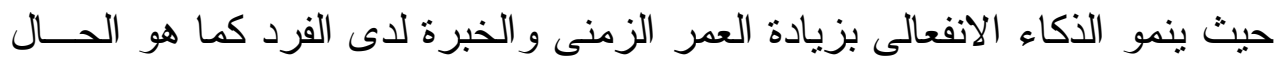

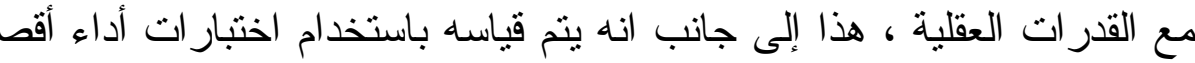

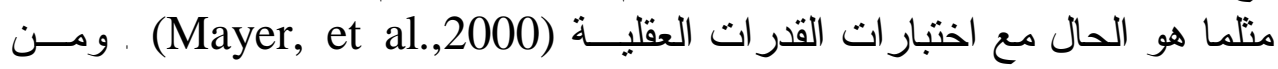

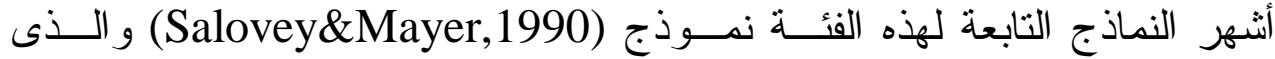
يفترض أن الذكاء الانفعالى يضم مجموعة من القدر ات هى :

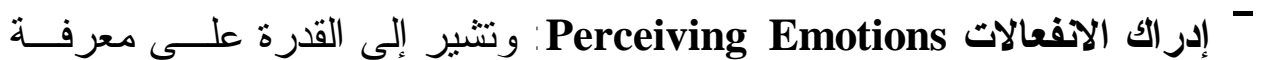

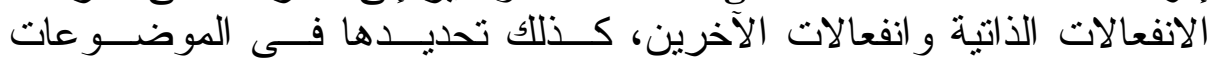

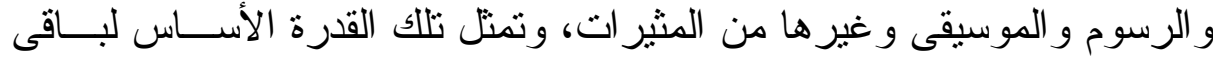

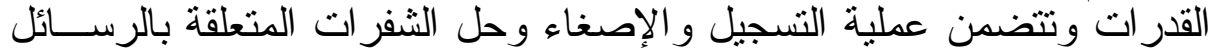

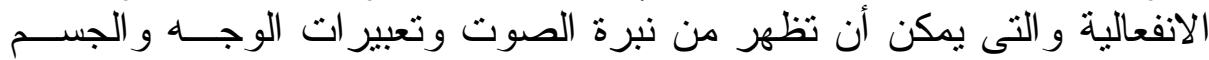

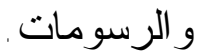

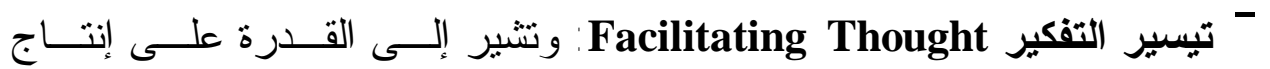
و استخدام المشاعر وتوظيفها لتيسير النمو المعرفى وحل المشكلات.

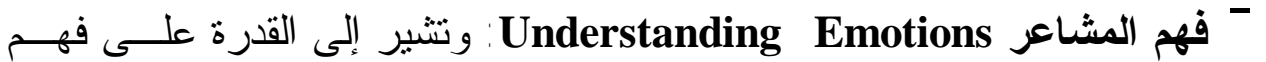

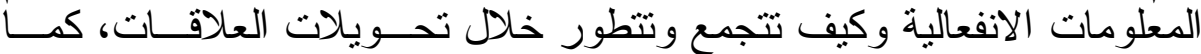
تتضمن فهم المعانى الانفعالية ، والعلاقات بين الانفعالات

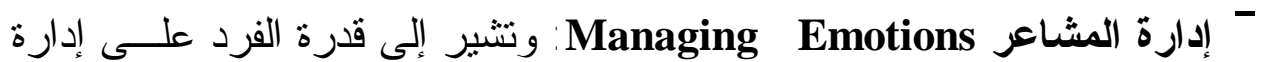
مشاعره الذانية و إدارتها لدى الآخرين.

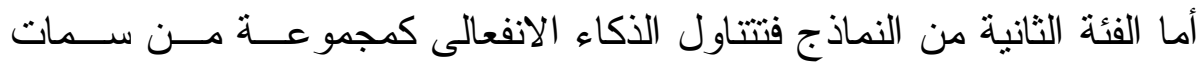

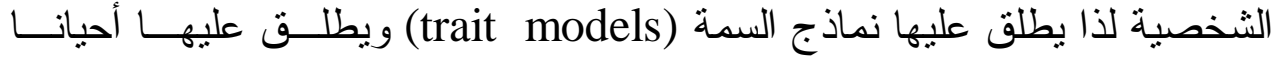

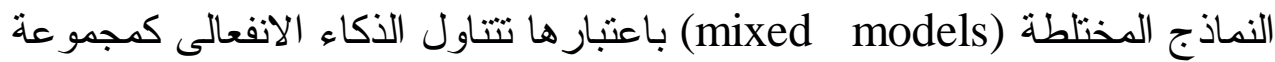

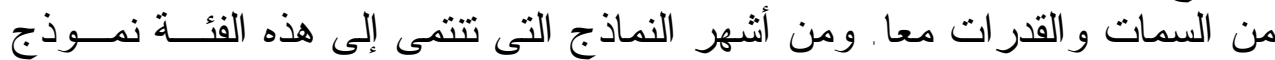

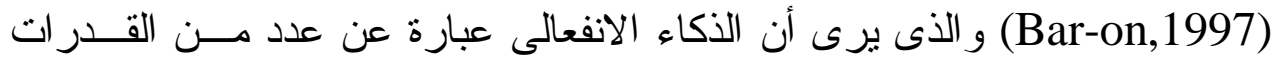
غير المعرفية المؤثرة على سلوك الأفر ادوتضماه الانفي

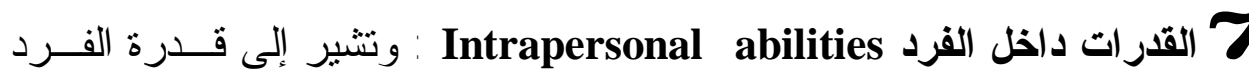

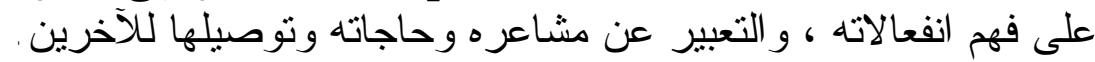

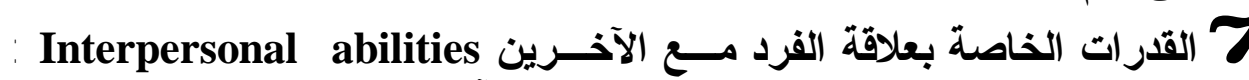

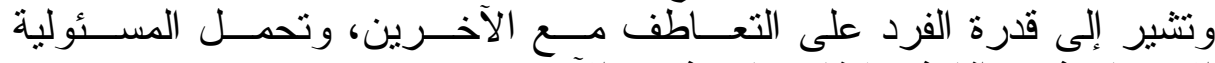
الاجتماعية ، و إقامة علاقات ناجحة مع الآخرين.

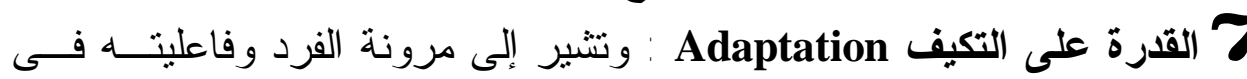
التعامل مع التغير ات و الايجابية فى التعامل مع المشكلات اليومية.

\section{1.}

سئستة دوأسأت عربية في التزبية وعنم النففي (ASEP) 


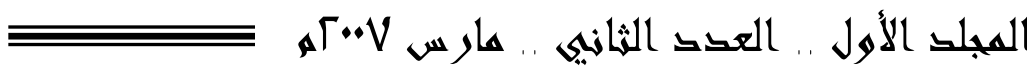

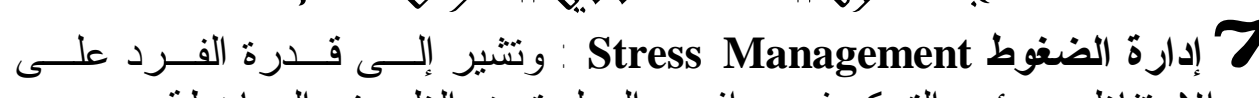

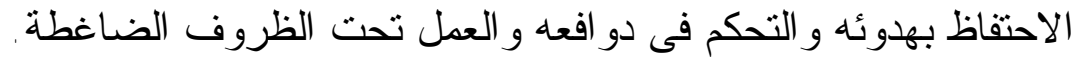

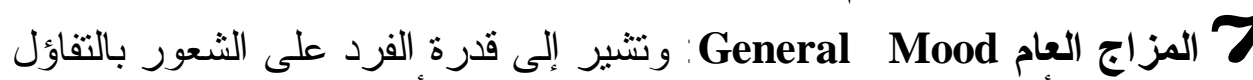

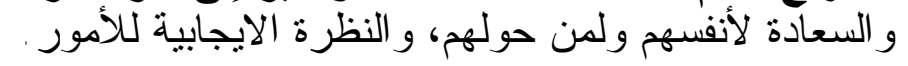

\section{• • مداخل قياس الذكاء الانفعالى :}

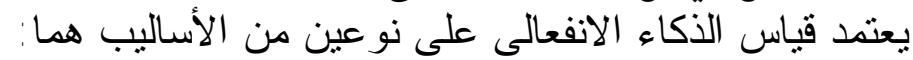

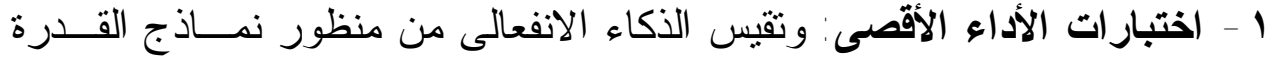

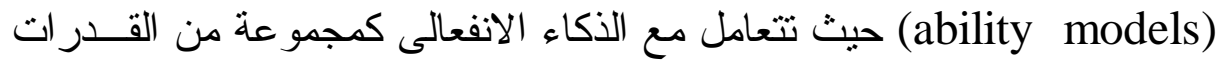

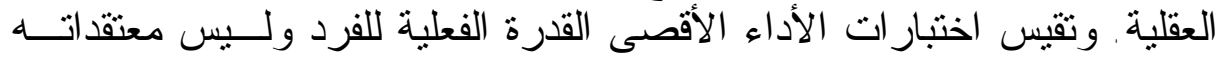

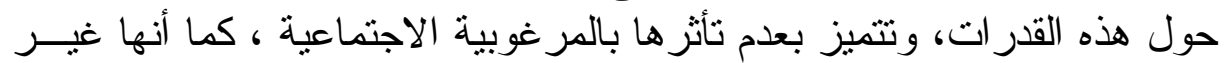
قابلة للتزبيف ومن أنتهر هذه والاختبار ات اختبــار (Mayer, et al.,2002b)

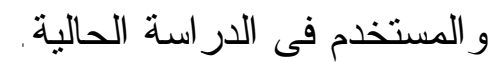

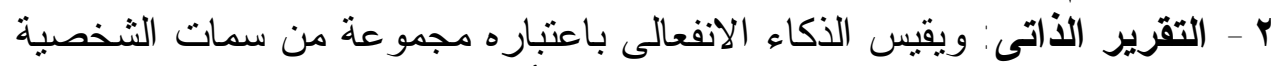
كما تشير نماذج السمة (trait models) ، أو القدر ات و و السمات معات معا كما نشير

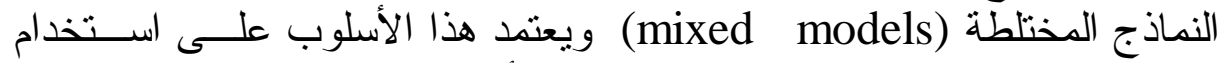

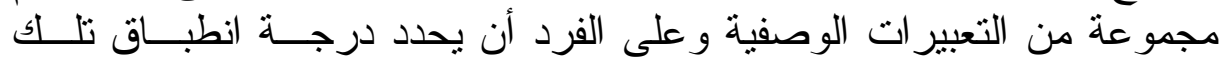

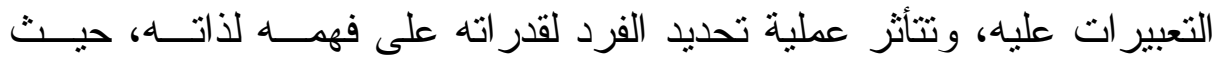

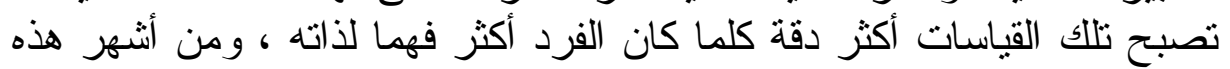
المقاييس (Bar-on,2000).

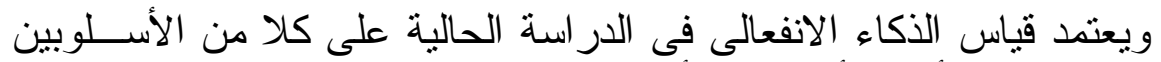

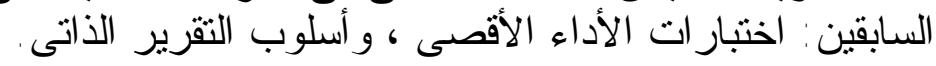

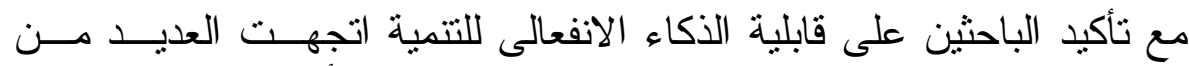

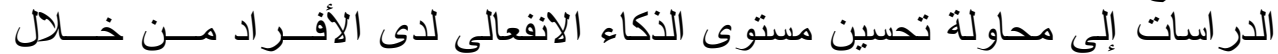

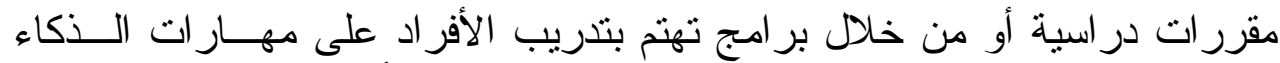

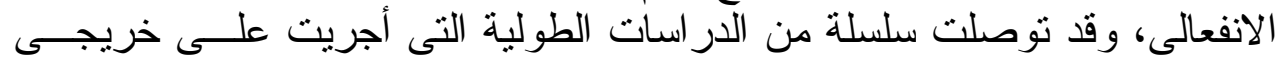

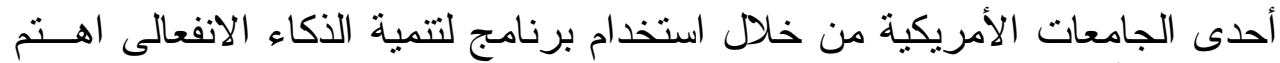

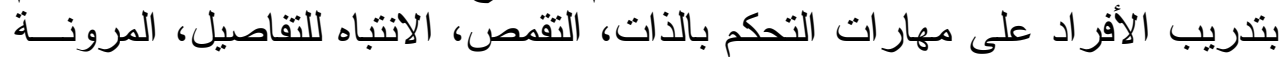

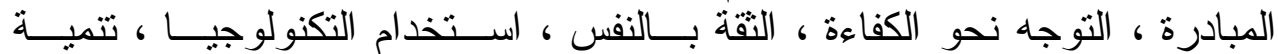

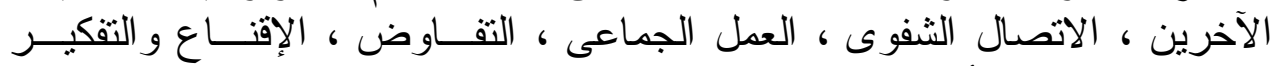

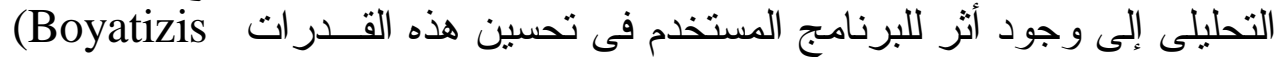
5) et al,1995; Boyatzis et al,1996;Boyatzis et al, in press)

\section{1}

سلسلة دوأسات عربية في الثتبية وعنم النففي (ASEP) 


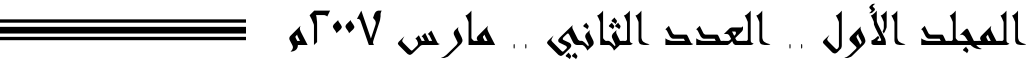

بينت در الســة (Richardson\& Evans,1997) ، كمـــا أدى تــدريب الأطفــال

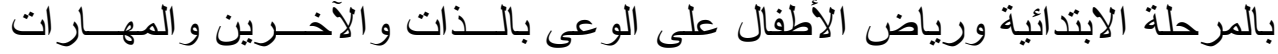

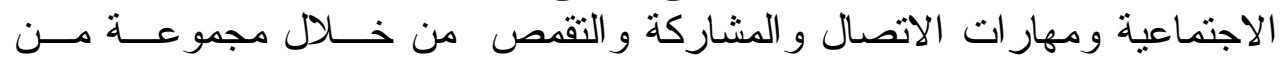

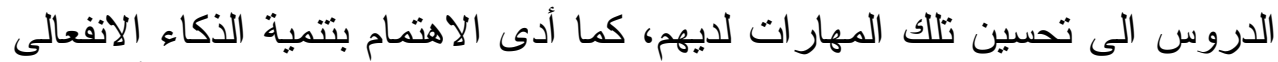

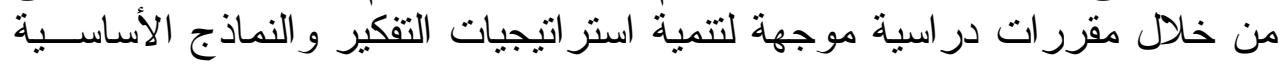

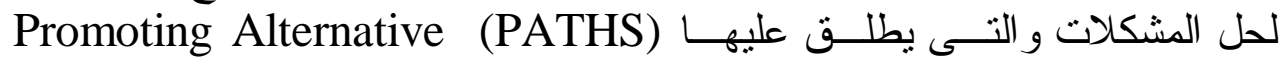
Thinking Strategies

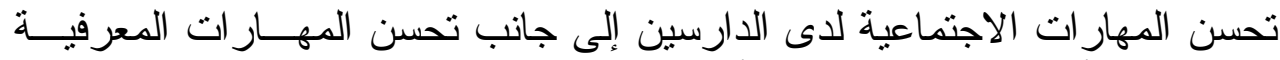

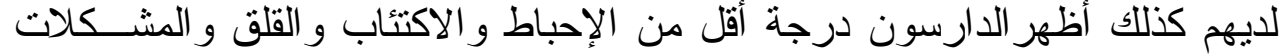

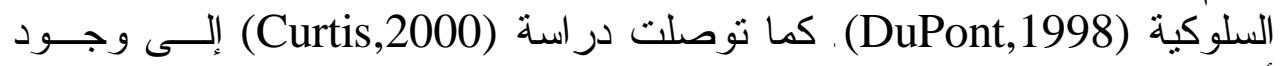

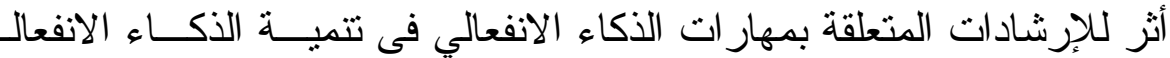

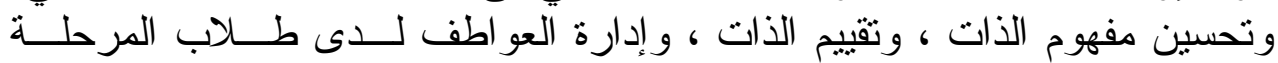

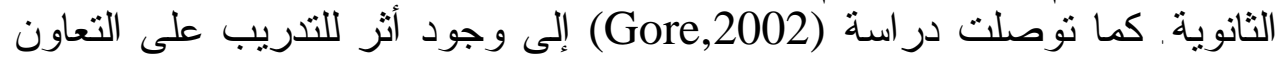

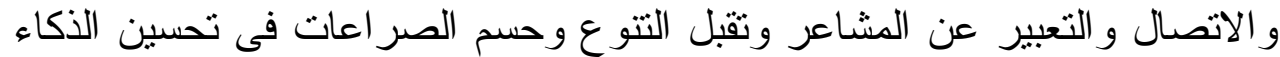

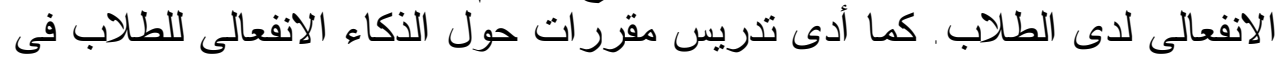

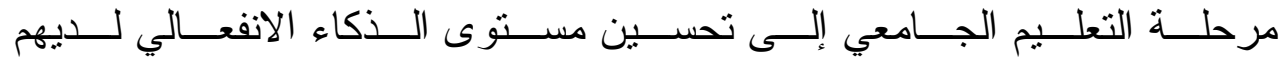

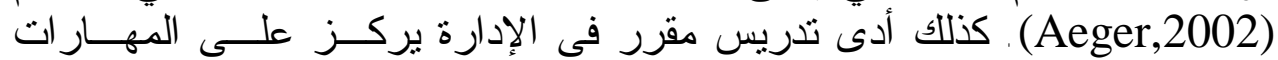

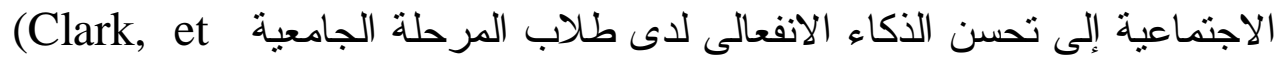

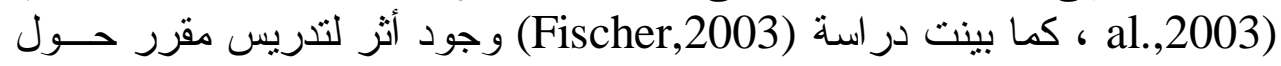

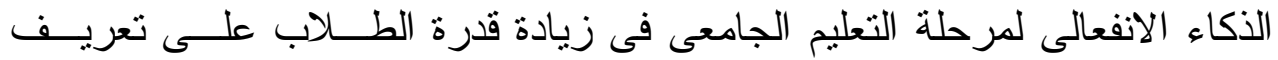

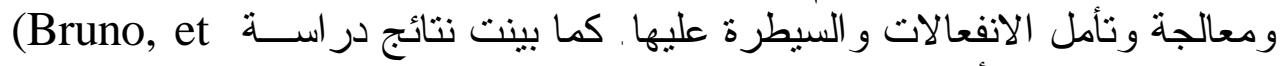

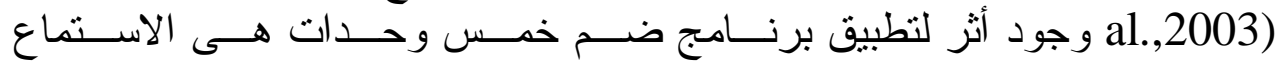

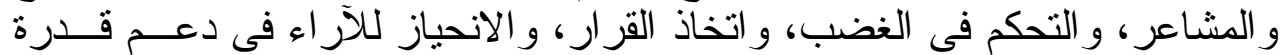

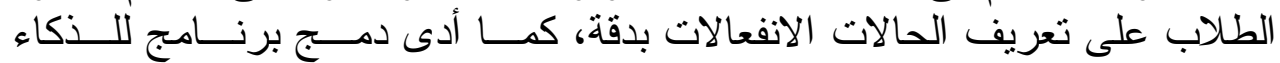

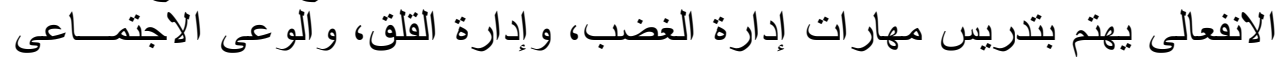

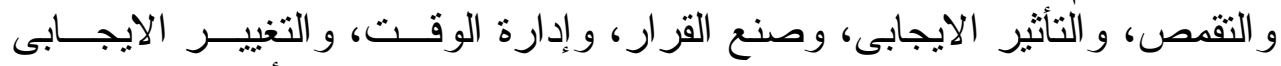

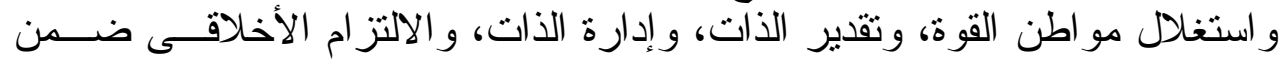

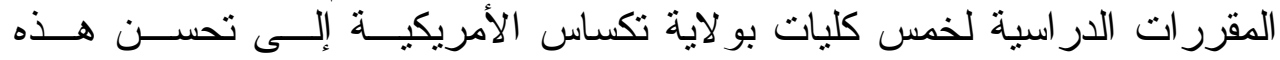

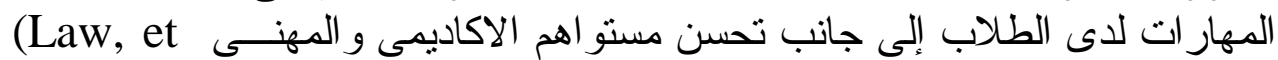

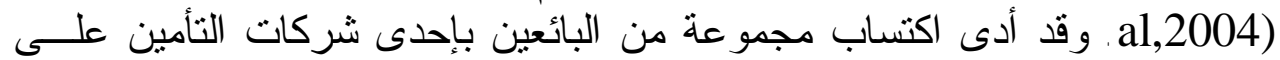

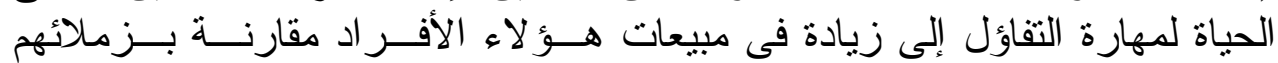

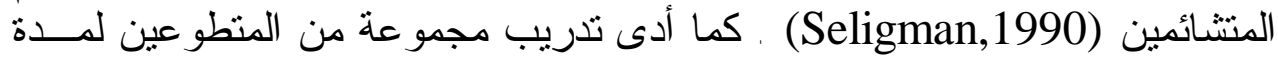

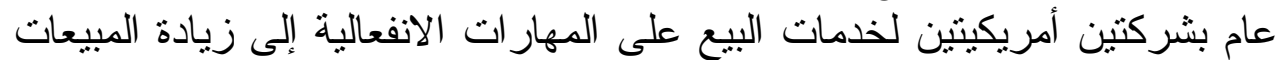

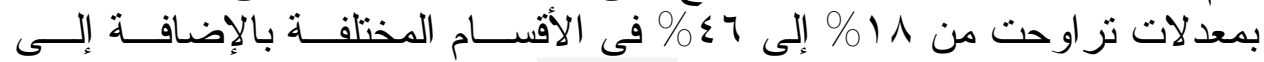

\section{$11 Y$}

سلسية دوأسأت عربية في الثتبية وعنم ألنفي (ASEP) 
ב

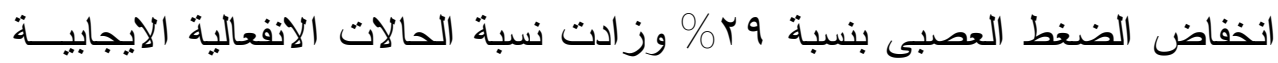

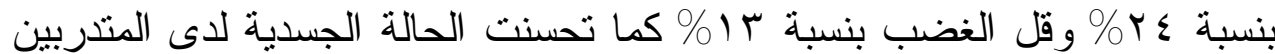
بصورة دالة (Luskin et al.,2005).

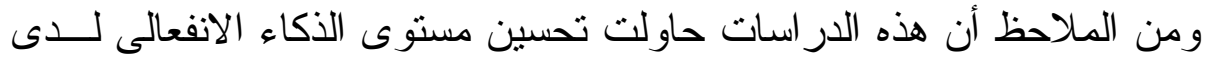

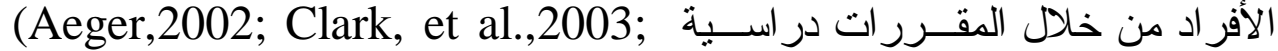
DuPont,1998; Fischer,2003; Richardson\& Evans,1997) خلال بر امج تدرييية معدة لهذا الغــرض Boyatizis et al, 1995; Boyatzis) et al, 1996; Boyatzis et al, in press; Bruno, et al., 2003 Gore, 2002; Curtis, 2000; Luskin et al., 2005; Seligman,1990; Law, et al,2004)

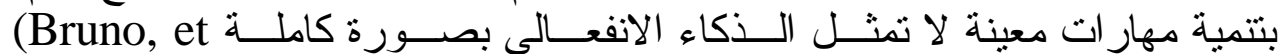
al.,2003; Clark, et al.,2003; Gore,2002; Seligman,1990) اعتمد كثير منها على مؤشرات غير مباشرة لبيان فاعلية التدريب كالاعتماد علـى ألى إنى مؤشر نسبة المبيعات أو الاعتماد على ملاحظة أولئك المحيطين بالفرد أو استخدام

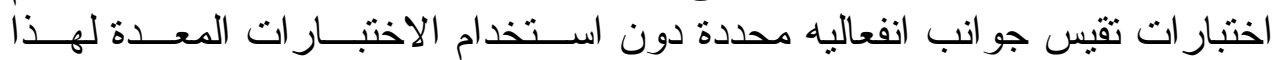

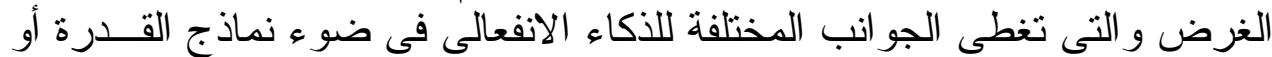

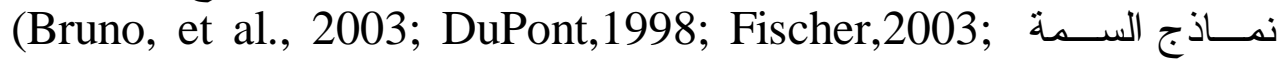
Law, et al, 2004; Luskin et al., 2005; Seligman, 1990)

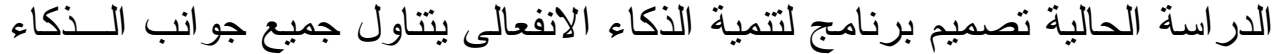

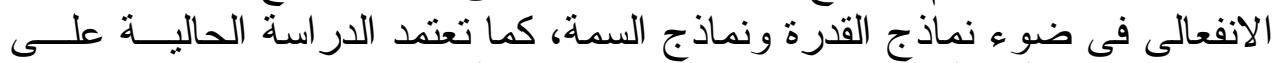

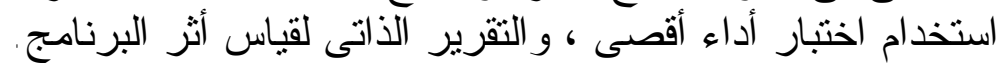

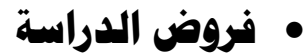

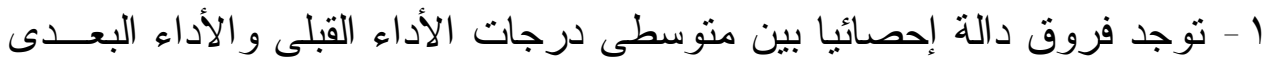

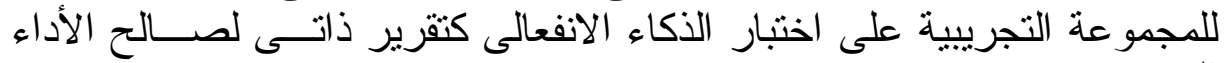

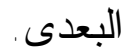

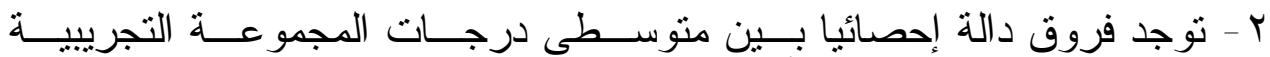

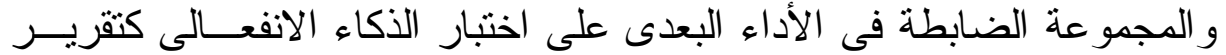
ذاتى لصالح المجمو عة التجريبية.

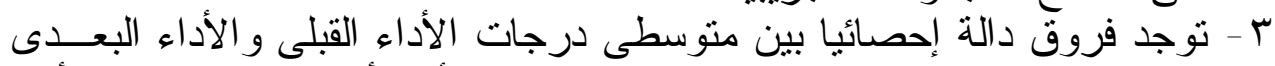

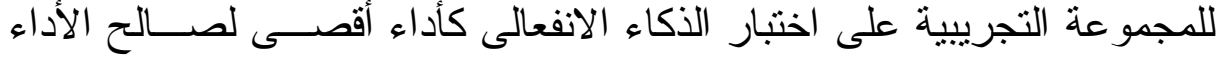
البعدى. - البع.

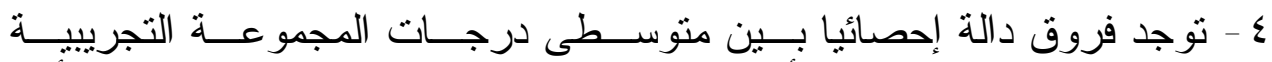

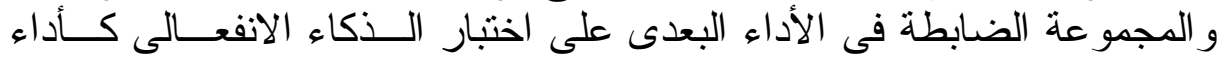
أقصى لصالح المجمو عة التجريبية. 


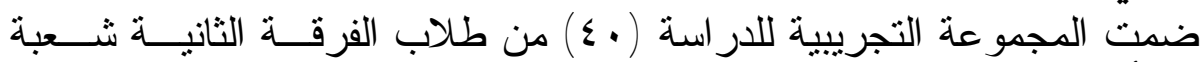

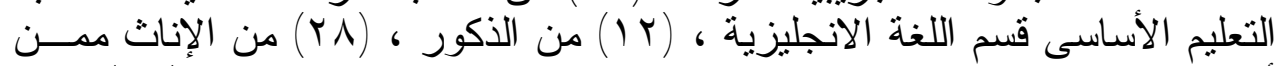

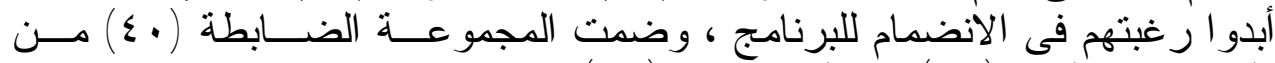
طلاب نفس القسم (IV) من الذكور ، و (rr (r) من الإناث.

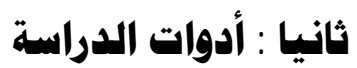

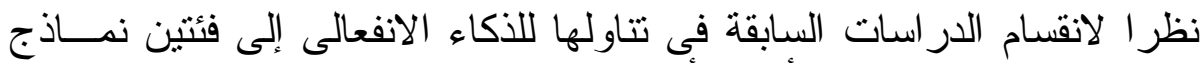

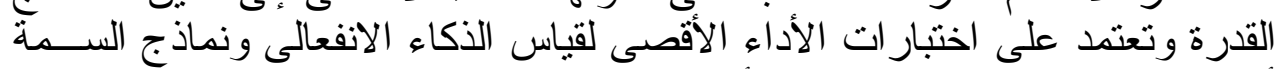

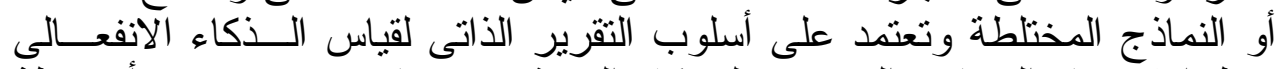

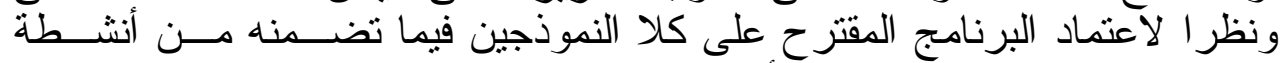

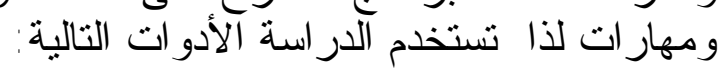

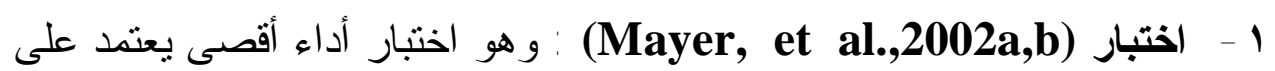

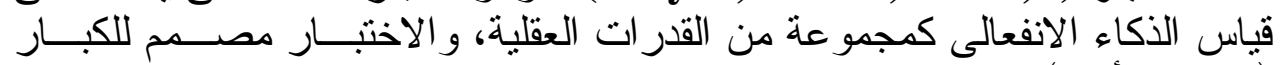

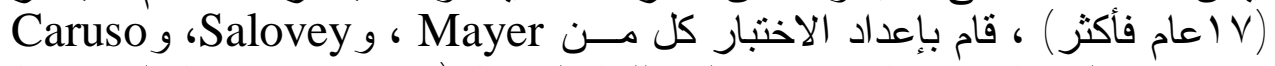

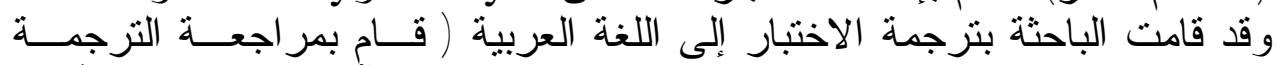

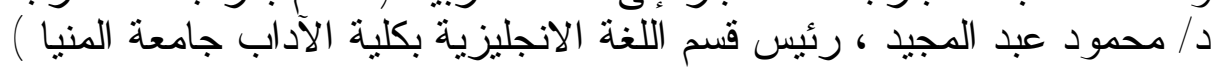

$$
\text { ويضم الاختبار ( (1 ) ) مفردة تنتمى إلى مجالين هما: }
$$

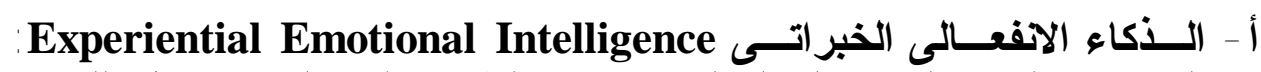

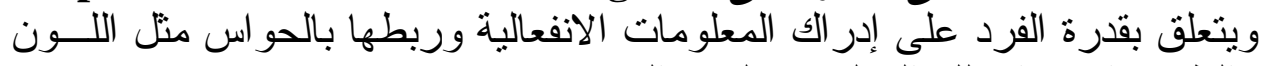

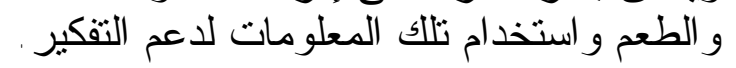

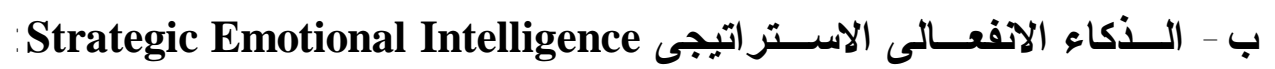

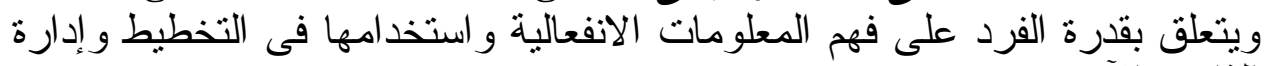

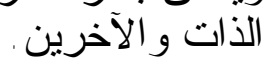
ويقيس الاختبار أربعة أبعاد للأكاء الانفعالى هى:

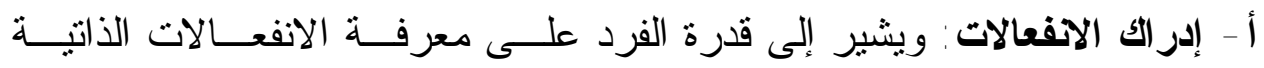

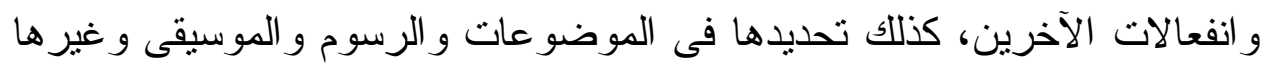

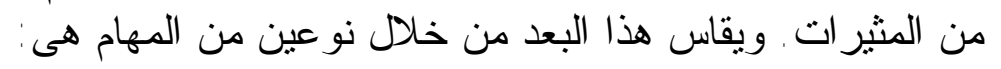

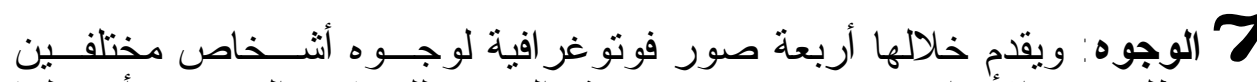

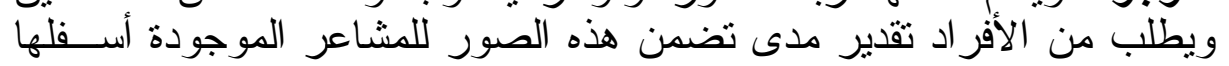

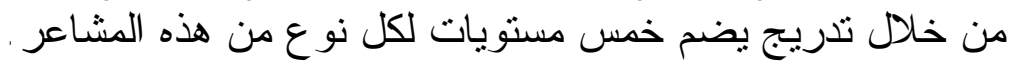

\section{$11 \varepsilon$}

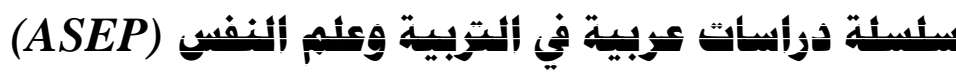




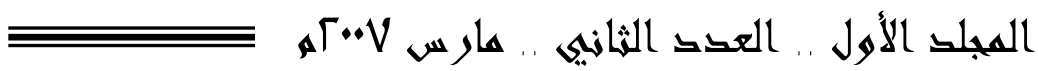

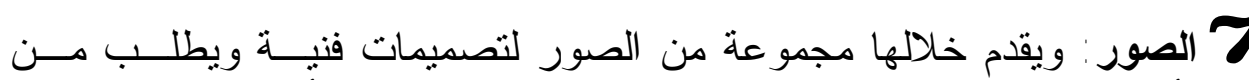

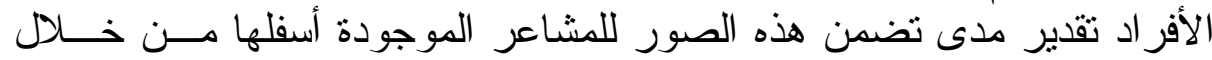

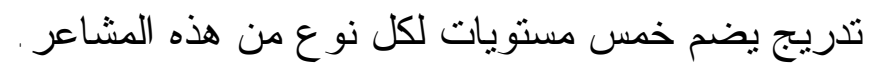

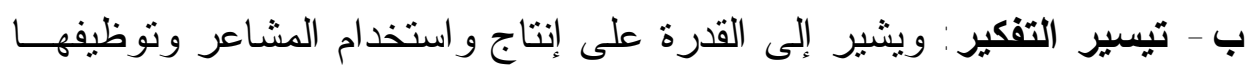

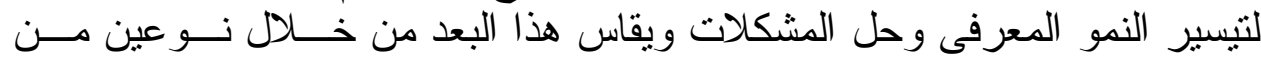

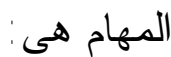

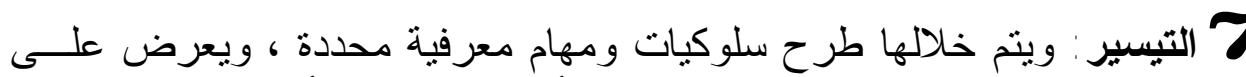

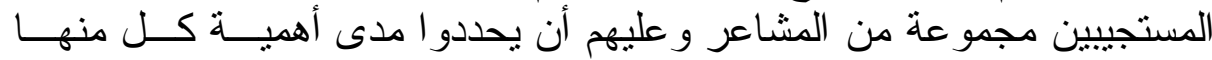

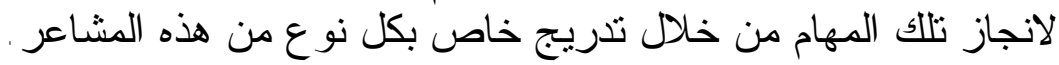

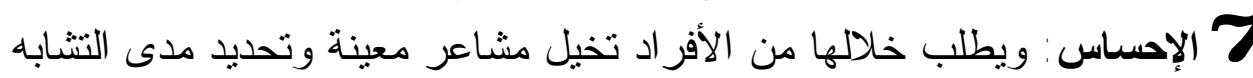

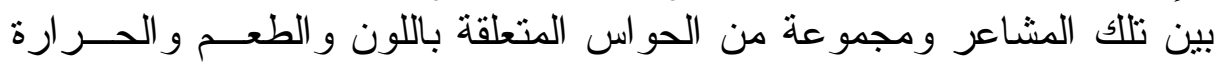

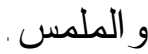

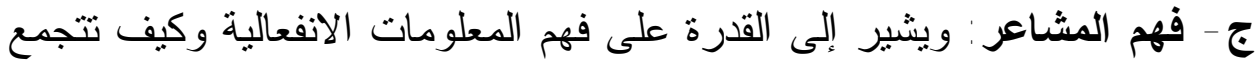

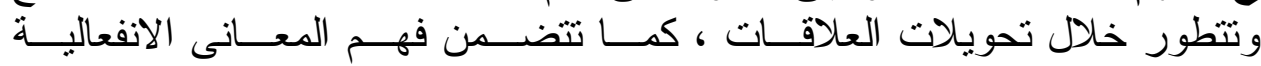
و العلاقات بين الانفعالات . ويقاس هذا البعد من خلال نو عين من المهام هى:

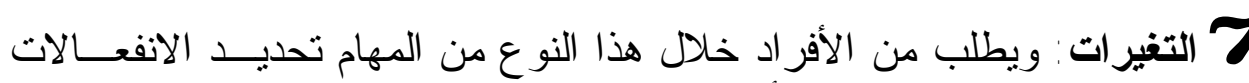
التى قد تتطور من انفعالات أخرى.

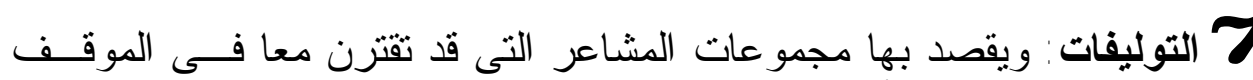

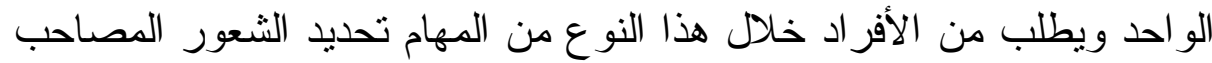
لمجموعة من المشاعر النى يتم تحديدها للمستجيبين. دـ - إدارة المشاعر: يثير إلى قدرة الفرد على تعديل انفعالاته و انفعالات الآخرين

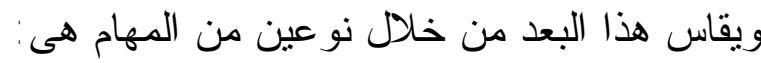

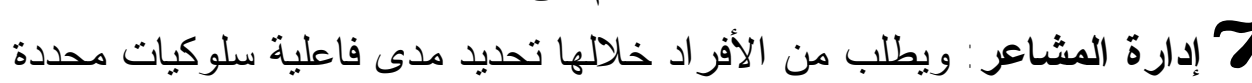

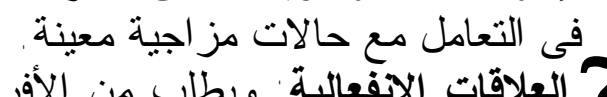

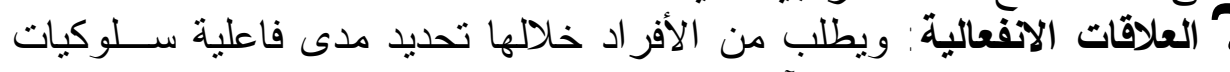

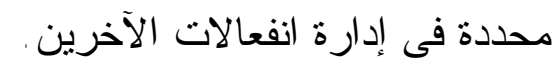
: تصحيح الاختبار

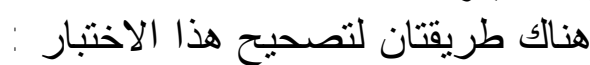

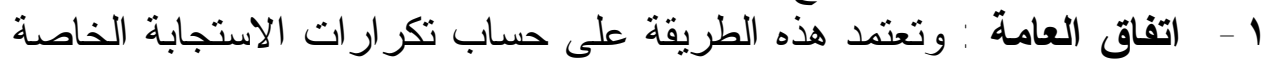

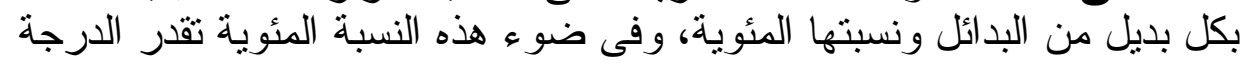


ב昰

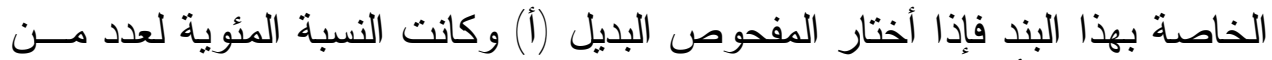

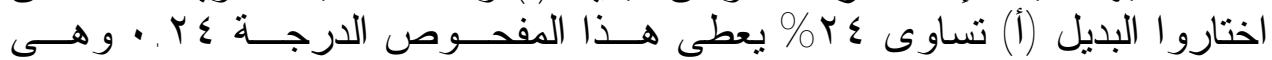

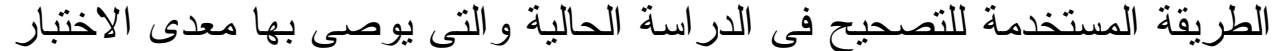

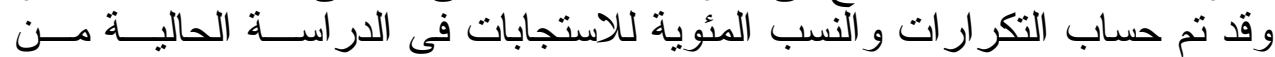

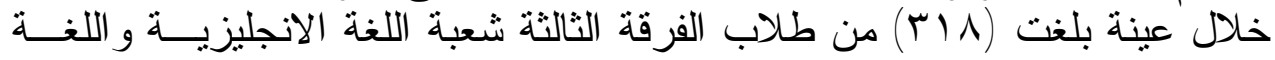
الفرنسية وطلاب الفرقة الثانية شعبة التعليم الابتدائى قسم اللغة الانجليزية وطلاب

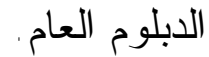

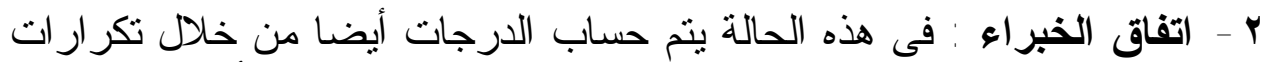

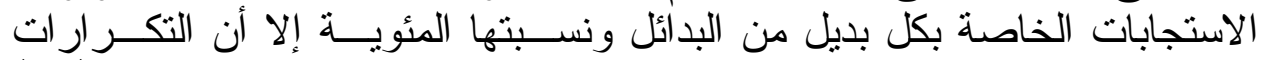
و النسب المئوية هنا ليست من خلال استجابات العامة بل تخص استــت التجابات (Y)

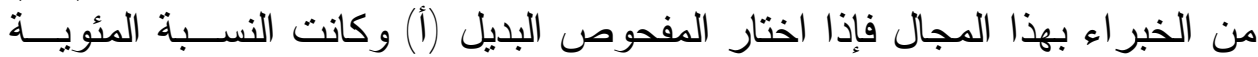

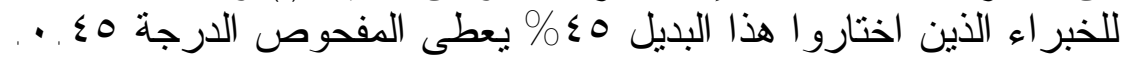

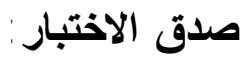

قام معدو الاختبار بحساب الصدق باستخدام عدة طرق أهمها:

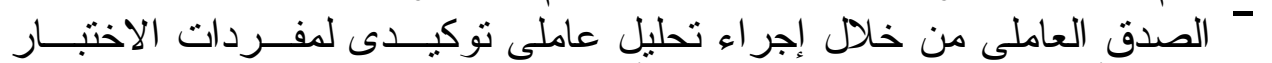

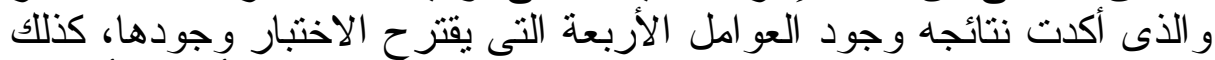

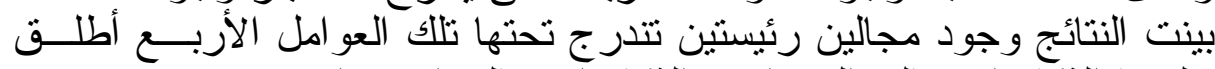

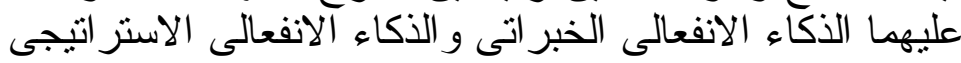

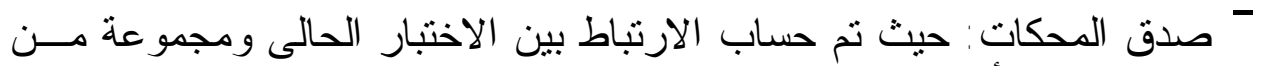

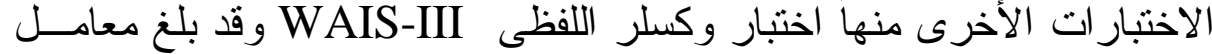

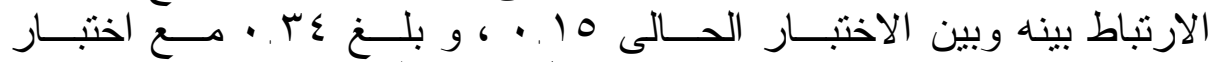
Bar-on و Cattell's Scale B(IQ)

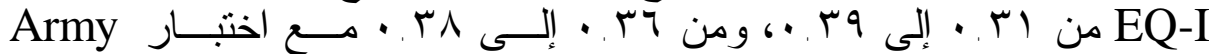
Alpha Vocabulary

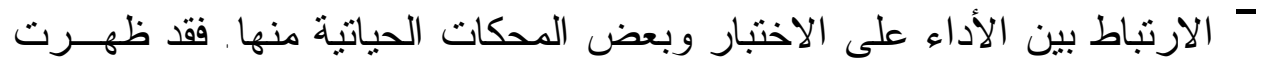

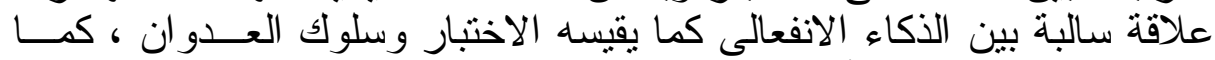

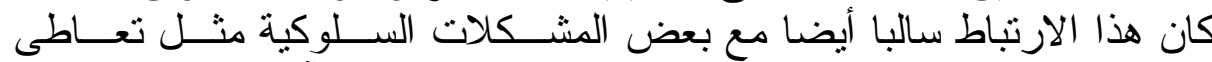

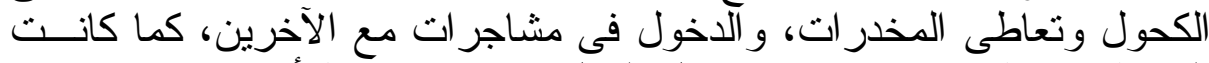

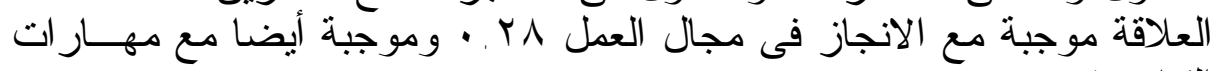

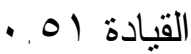
ثبات الاختبار : ت إدة

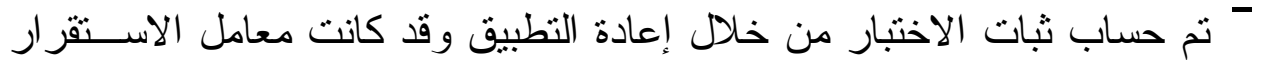

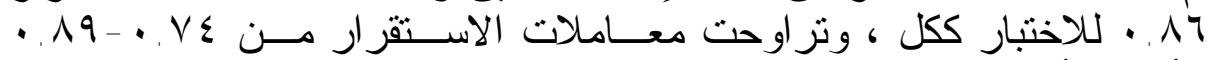

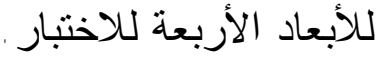




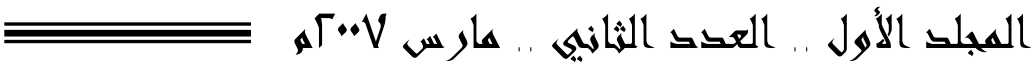

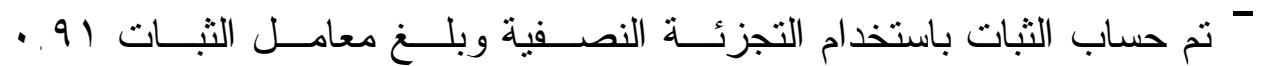

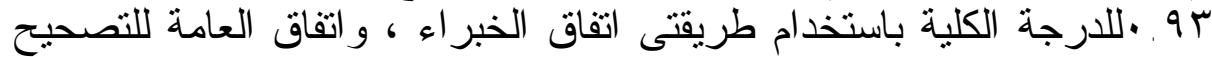

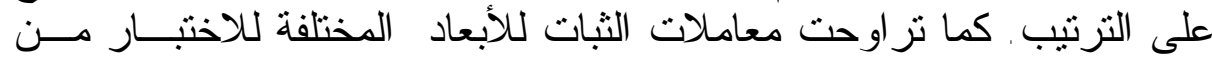

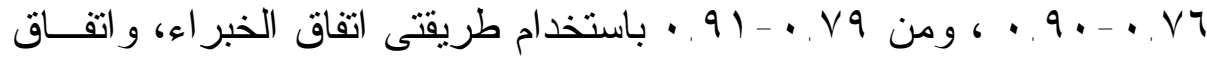
العامة للتصحيح على الترتيب.

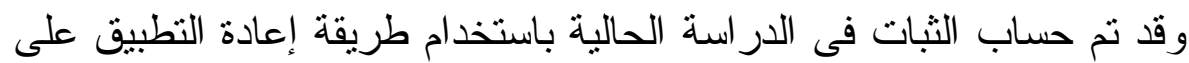

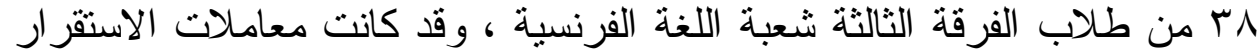

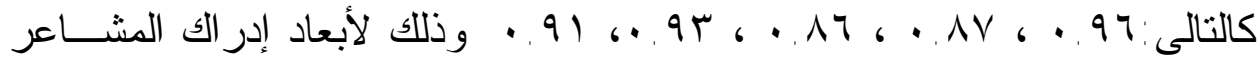

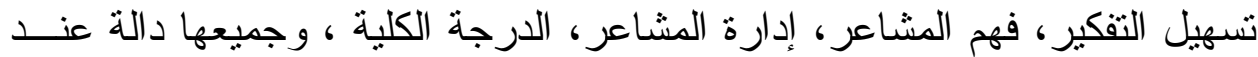

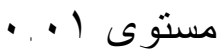

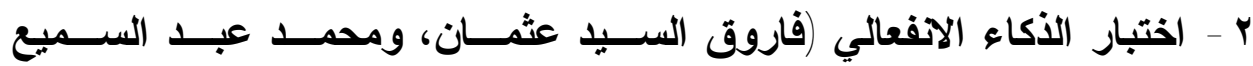

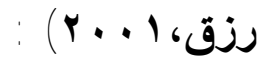

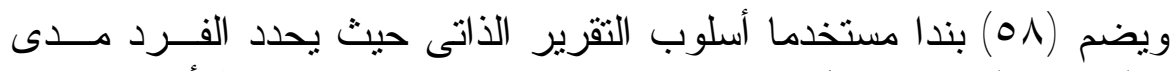

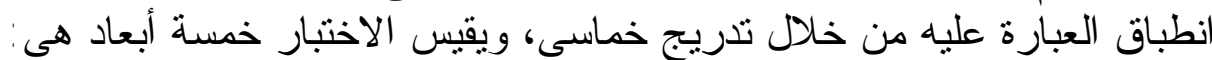

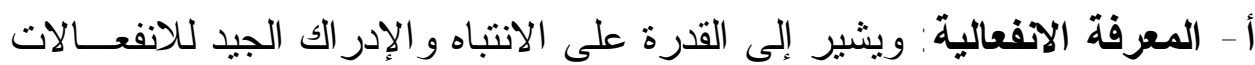
و المشاعر الذاتية وحسن التمييز بينها و الوعى بالعلاقة بين الأفكـار و المشــــاعر الإتر و والأحداث

ب - إدارة الانفعـالات: ويشير إلى القدرة على التحكم فــى الانفعـالات الســليية

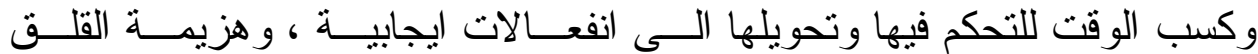
و الاكتئاب وممارسة مهار ات الحياة بفاعلية.

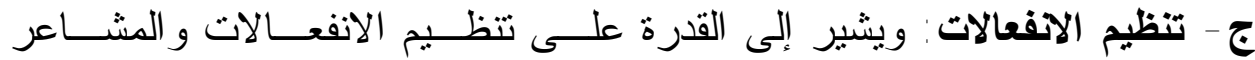

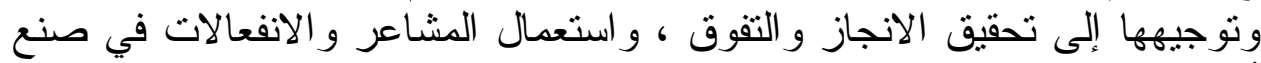

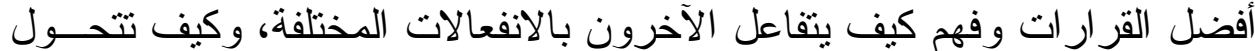
الانفعالات من مرحلة إلى أخرى.

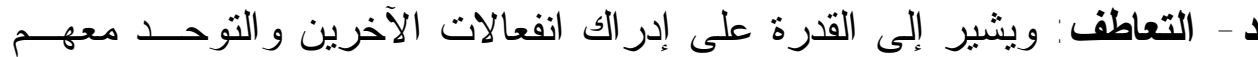

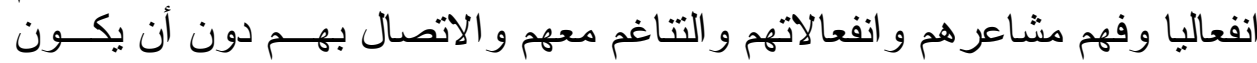
السلوك محمل بالانفعالات الثخصية.

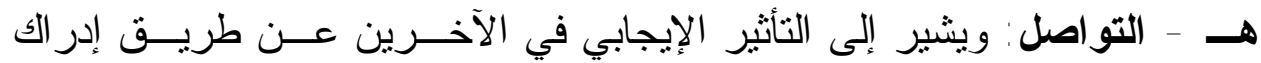

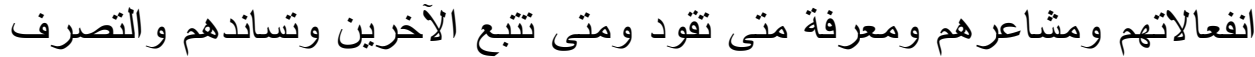
معهم بطريقة لائقة. 


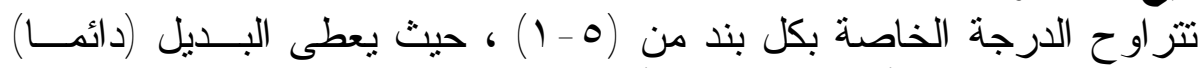

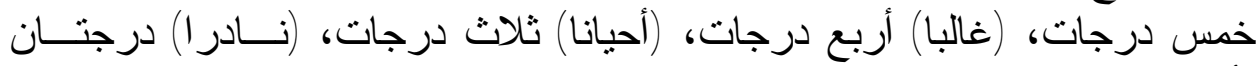

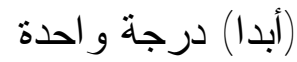

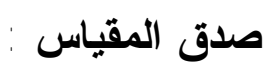

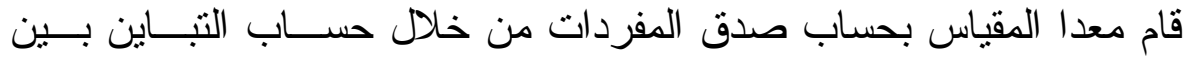

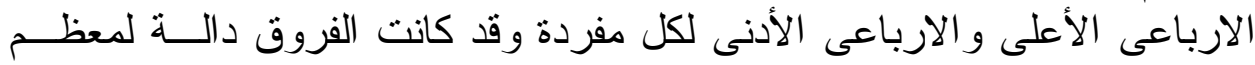

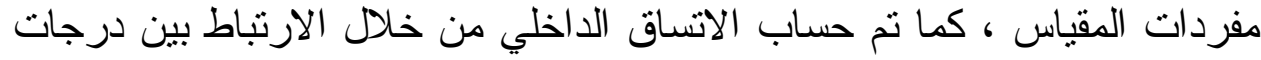

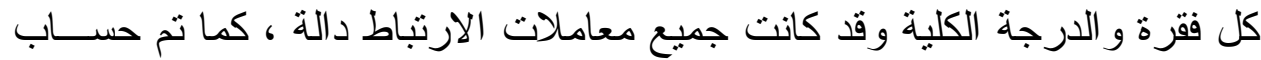

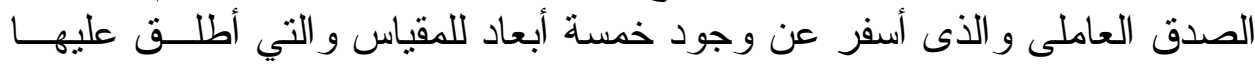

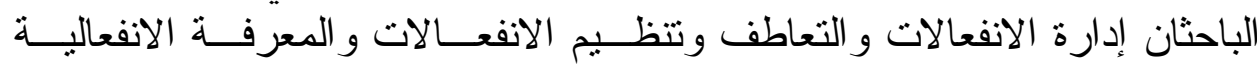

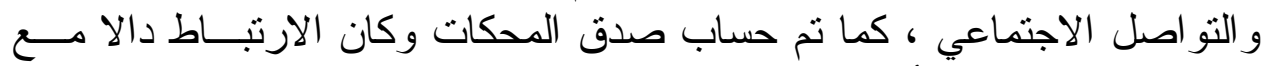

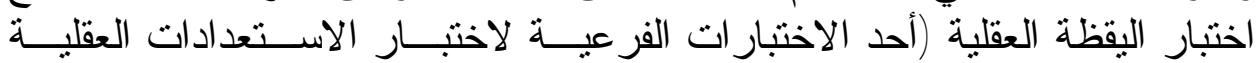

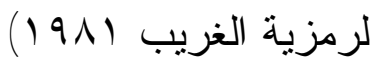

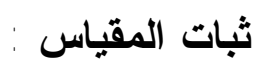

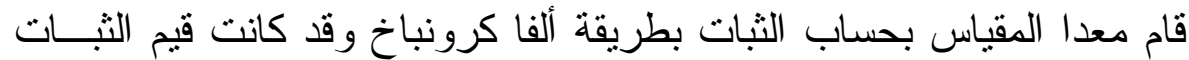

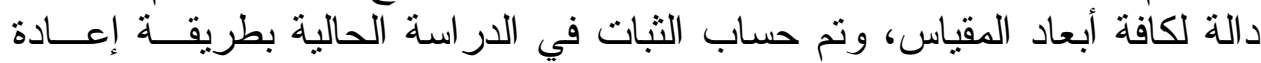

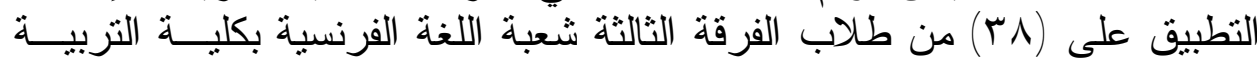

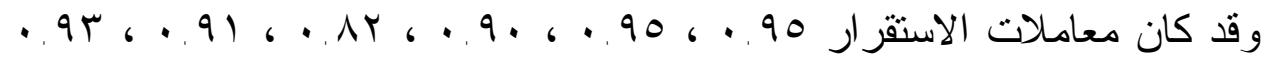

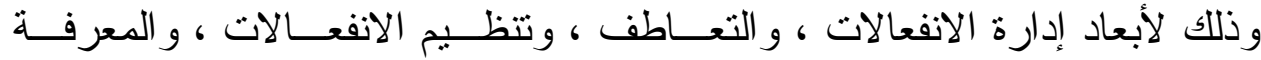

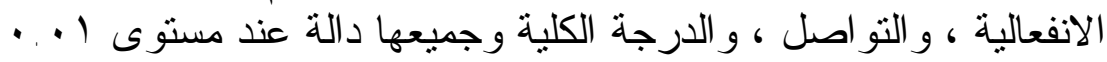

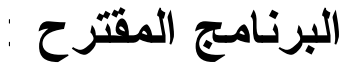

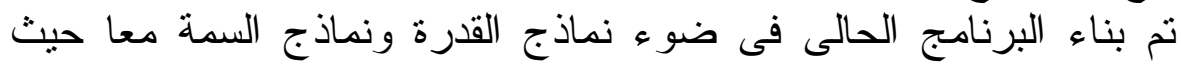

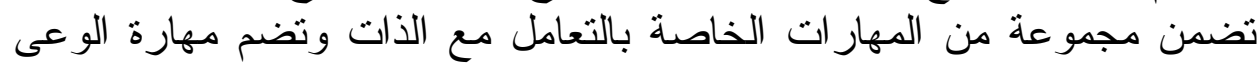

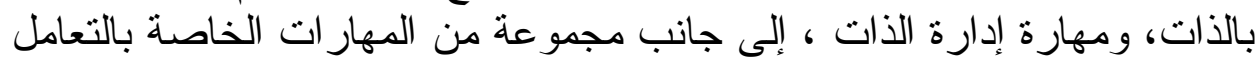

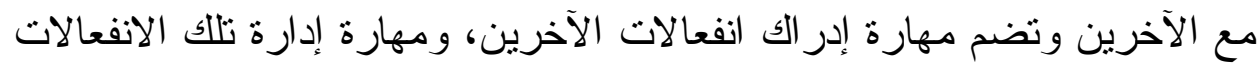
(Allen,2002;Carnegie,1990;Chandler,2004;Ekman\& Davidson,

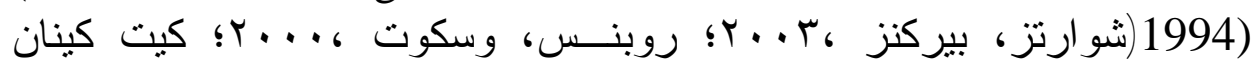
.$(1999$

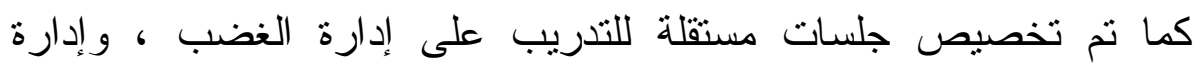
الضغط العصبى و القلق، إثارة الدافعية الذاتية ، الثقة بالنفس ضمن التناريب على الثى

\section{1}

سئستة دوأسأت عربية في التزبية وعنم النففي (ASEP) 


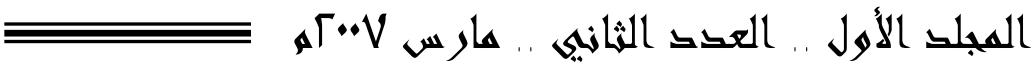

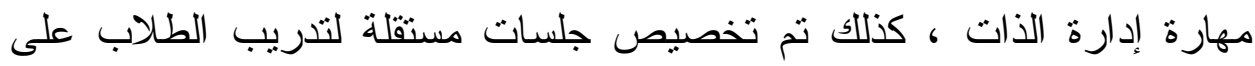

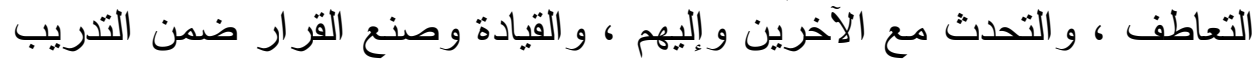

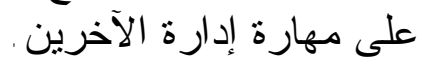

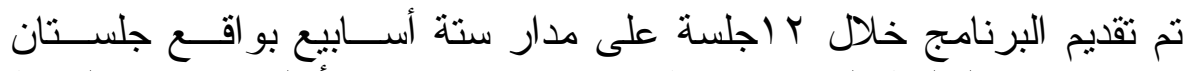

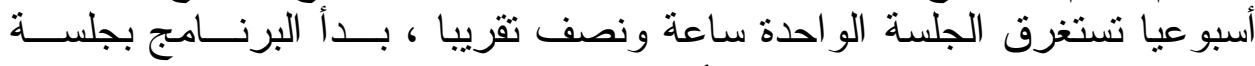

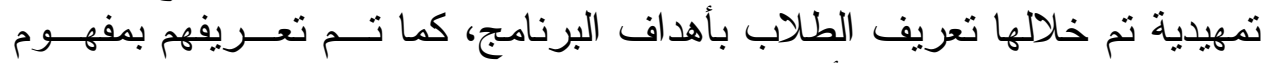

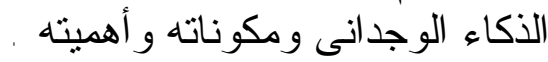

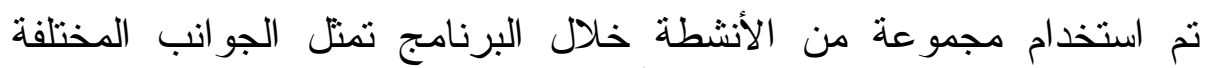

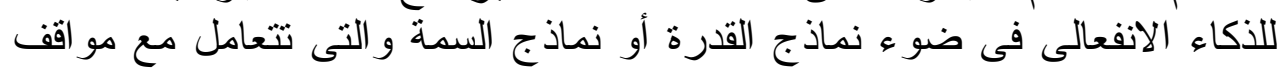

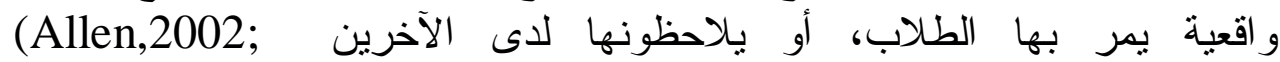
Carnegie,1990; Chandler,2004; Ekman \& Davidson, 1994)

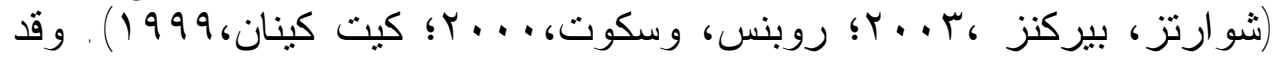

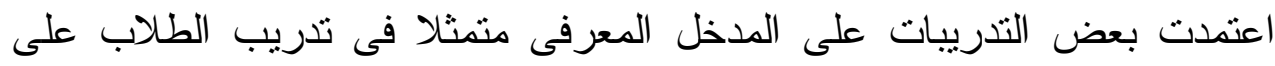

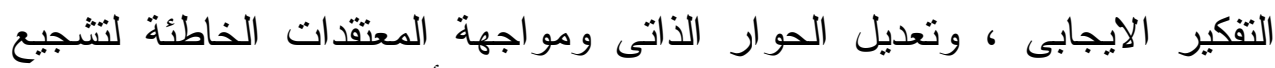

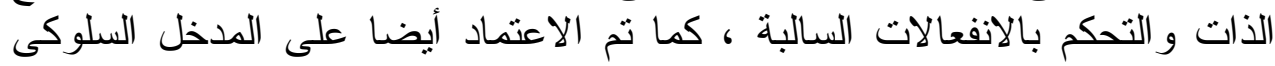

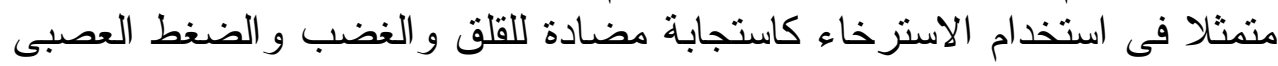
.(Madders, 1988; Trotter, 1999)

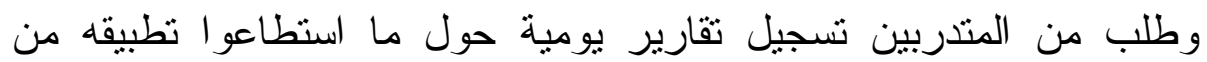

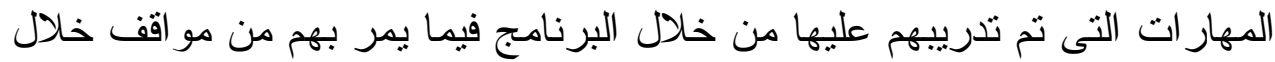

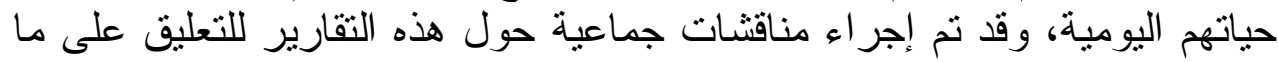

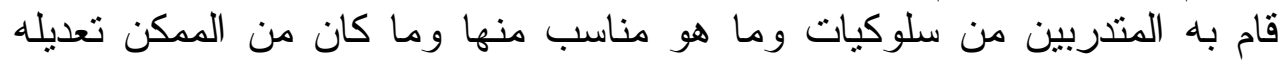

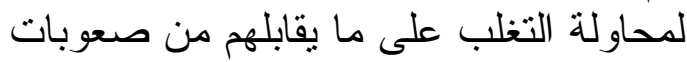

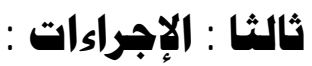

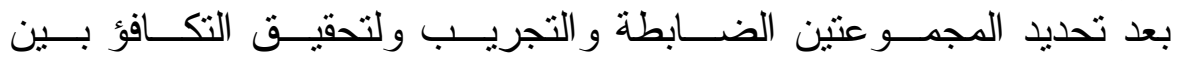

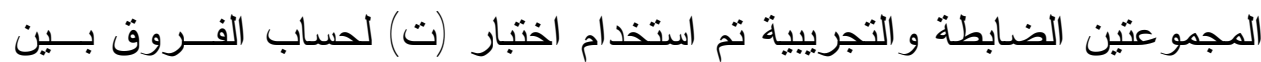

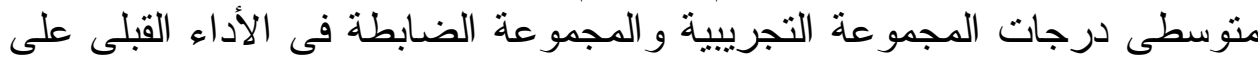

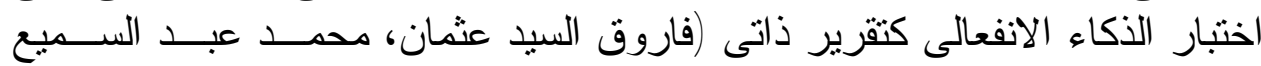

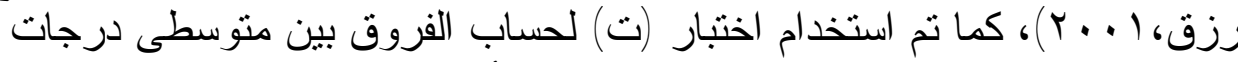

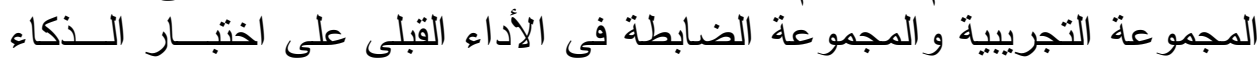

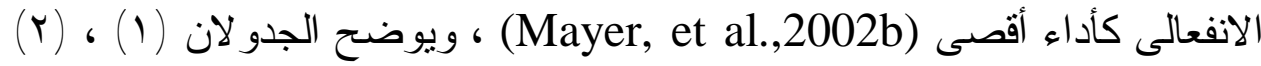
تللك النتائج . 


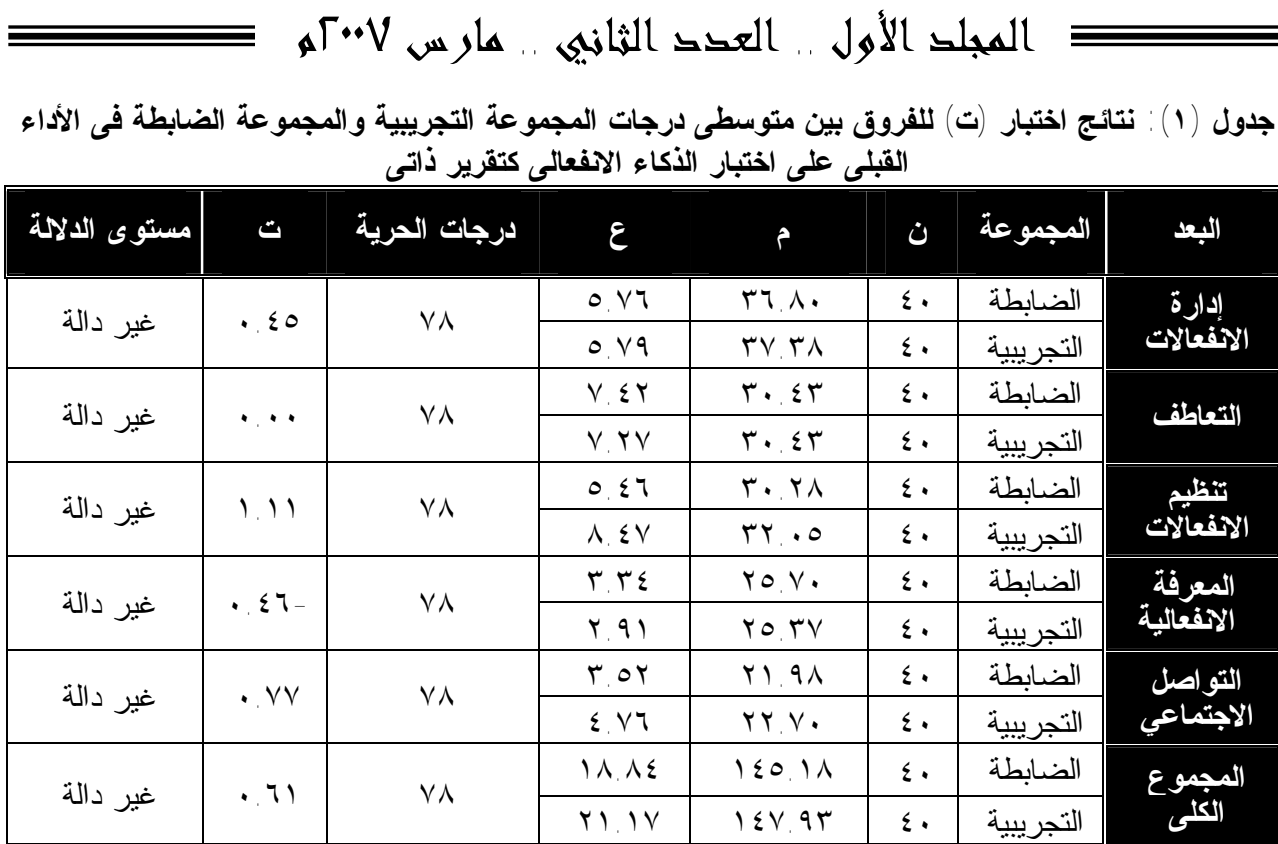

جدول (Y) : نتائج اختبار (ت) للفروق بين متوسطى درجات المجموعة التجريبية والمجموعة الضابطة فى الأداء

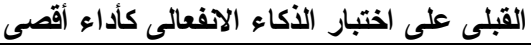

\begin{tabular}{|c|c|c|c|c|c|c|c|}
\hline مستوى الدلاية & $ت$ & درجات الحرية & $\varepsilon$ & r & ن & المجموعة & البعد \\
\hline \multirow{2}{*}{ غير دالة } & \multirow{2}{*}{. } & \multirow{2}{*}{$\vee \wedge$} & 1.19 & IE.VT & $\varepsilon$. & الضابطة & \multirow{2}{*}{ الإفعالات } \\
\hline & & & 1.79 & $1 \leq .74$ & $\varepsilon$. & التجريبية & \\
\hline \multirow{2}{*}{ غير دالة } & \multirow{2}{*}{$.0 \mathrm{~V}$} & \multirow{2}{*}{ v^ } & 1.7 & $9.0 \leqslant$ & $\varepsilon$. & الضابطة & \multirow{2}{*}{ تشيكيل } \\
\hline & & & $1 . \leqslant 0$ & $9 . V r$ & $\varepsilon$. & التجريبية & \\
\hline \multirow{2}{*}{ غير دالة } & \multirow{2}{*}{.$M V$} & \multirow{2}{*}{$\vee \wedge$} & $1.7 \pi$ & $1 T . \Sigma V$ & $\varepsilon$. & الضابطة & \multirow{2}{*}{ الإفعالات } \\
\hline & & & $1 . r \varepsilon$ & 11.09 & $\varepsilon$. & التجرييية & \\
\hline \multirow{2}{*}{ غير دالة } & \multirow{2}{*}{$\because Y V-$} & \multirow{2}{*}{$\vee \wedge$} & $.9 \varepsilon$ & $\Lambda . M$ & $\varepsilon$. & الضابطة & \multirow{2}{*}{ الإفعالات } \\
\hline & & & $1 . \cdot v$ & N. Yo & $\varepsilon$. & التجرييية & \\
\hline \multirow{2}{*}{ غير دالة } & \multirow{2}{*}{$\because r}$. & \multirow{2}{*}{$\vee \wedge$} & r. $\varepsilon \varepsilon$ & $\leqslant 7, .0$ & $\varepsilon$. & الضابطة & \multirow{2}{*}{ الكجموع } \\
\hline & & & r.vq & $\{\zeta, Y\}$ & $\varepsilon$. & التجريبية & \\
\hline
\end{tabular}

ويتضح من الجداول (1) ، (r) (ب) عدم وجود فروق دالــة إحصـــائيا بــين

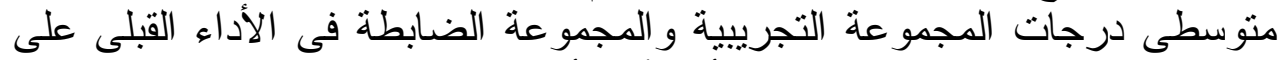

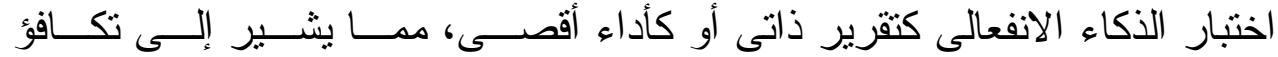

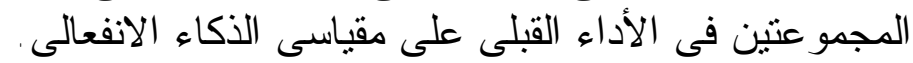

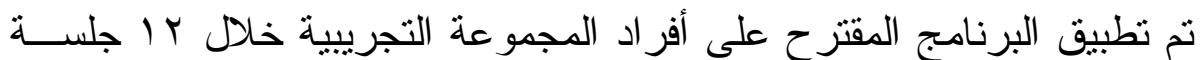

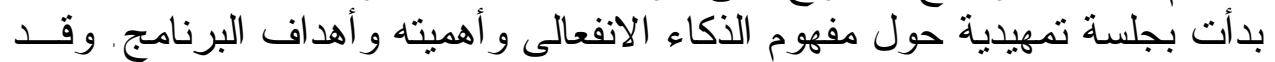

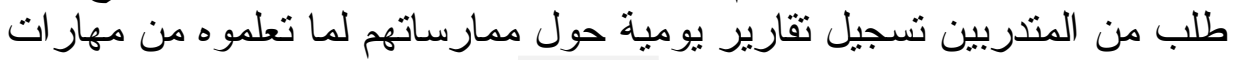

\section{Y.}

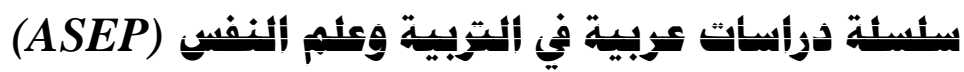




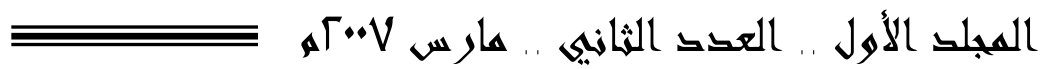

فيما يمر بهم من مو اقف الحياة اليومية، وقد تم مناقتنة هذه التقارير فى بداية كـلـل

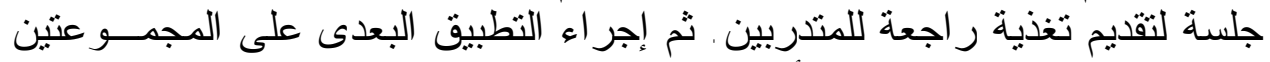
الضابطة و التجريبية باستخدام أدو ات الدربة استة

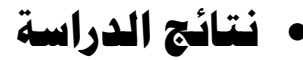

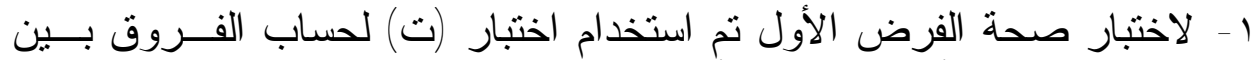

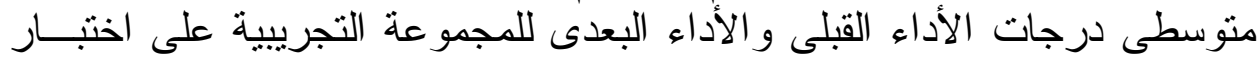

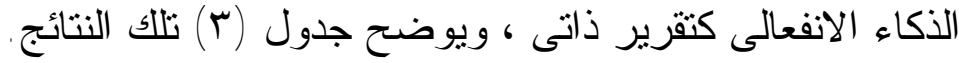

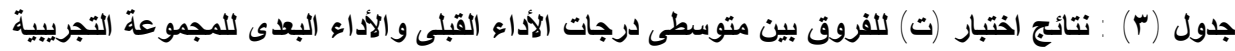
على اختبار الذكاء الافعالى كتقرير ذاتى الأى الأى

\begin{tabular}{|c|c|c|c|c|c|c|c|c|c|}
\hline التأتُّير & ريتا & مستوى الدلاية & $ت$ & الحرية & $\varepsilon$ & P & $\dot{0}$ & الأكاء & البعد \\
\hline \multirow[b]{2}{*}{ كبير } & \multirow[b]{2}{*}{$.0 Y$} & \multirow{2}{*}{ دالة عند } & \multirow[b]{2}{*}{7.00} & \multirow[b]{2}{*}{ rq } & 0.19 & r. & $\varepsilon$. & القبلي & \multirow{2}{*}{ الإفعالات } \\
\hline & & & & & 7.11 & $\leqslant 0, \varepsilon$. & $\varepsilon$. & البعدى & \\
\hline \multirow[b]{2}{*}{ كبير } & \multirow[b]{2}{*}{. .01} & \multirow{2}{*}{ دالة عند } & \multirow[b]{2}{*}{$7 . \Sigma 1$} & \multirow[b]{2}{*}{$r q$} & $V . Y V$ & $\Gamma \cdot . \Sigma \Gamma$ & $\varepsilon$. & القبلى & \multirow[b]{2}{*}{ التعاطف } \\
\hline & & & & & 0.94 & ५.. 7. & $\varepsilon$. & البعدى & \\
\hline \multirow[b]{2}{*}{ كبير } & \multirow[b]{2}{*}{$\cdot, r}$. & \multirow{2}{*}{ دالة عندى } & \multirow{2}{*}{$\varepsilon . \cdot 1$} & \multirow{2}{*}{ rq } & $\Lambda . \leqslant V$ & ru. . 0 & $\varepsilon$. & القبلى & \multirow{2}{*}{ الآفعالاث } \\
\hline & & & & & T.Y & rq.7. & $\varepsilon$. & البعدى & \\
\hline \multirow[b]{2}{*}{ كبير } & \multirow[b]{2}{*}{$\because$ Vo } & \multirow{2}{*}{ دالة عندى } & \multirow[b]{2}{*}{$1 \cdot . \wedge \varepsilon$} & \multirow[b]{2}{*}{ rq } & 4.91 & ro.r. & $\varepsilon$. & القبلى & \multirow{2}{*}{ الاحفعرفة } \\
\hline & & & & & r.l & & $\varepsilon$. & البعدى & \\
\hline \multirow[b]{2}{*}{ كبير } & \multirow[b]{2}{*}{$\cdot \leq \leqslant$} & \multirow{2}{*}{ دالة عند } & \multirow[b]{2}{*}{0.1 . } & \multirow[b]{2}{*}{ rq } & $\Sigma . V T$ & r..V. & $\varepsilon$. & القبلى & \multirow{2}{*}{ الاجتماعل التيل } \\
\hline & & & & & $\Sigma . V Y$ & Y^.VT & $\varepsilon$. & البعدى & \\
\hline \multirow[b]{2}{*}{ كبير } & \multirow{2}{*}{.70} & \multirow{2}{*}{ دالة عند } & \multirow{2}{*}{$\Lambda . \Sigma Y$} & \multirow{2}{*}{ rq } & YI. IV & $1 \leqslant V .94$ & $\varepsilon$. & القبلى & \multirow{2}{*}{ المجموع } \\
\hline & & & & & 19.71 & 1100.0. & $\varepsilon$. & البعدى & \\
\hline
\end{tabular}

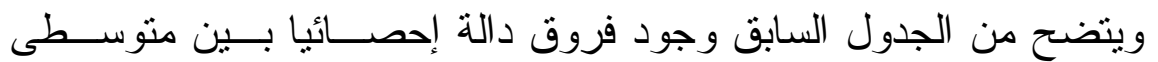

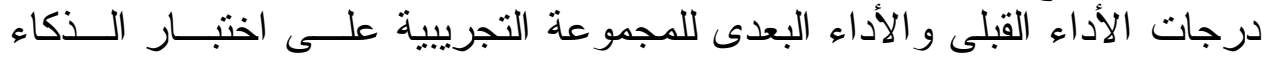

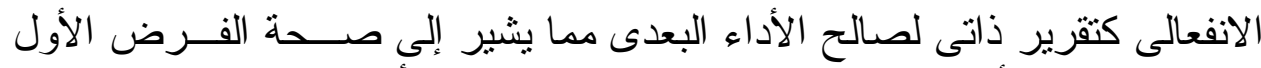

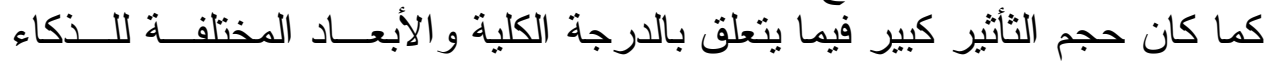

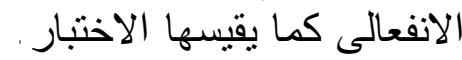

\section{$|Y|$}

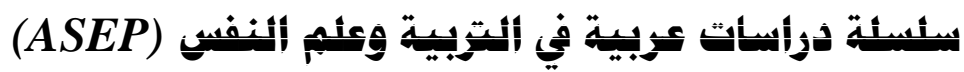




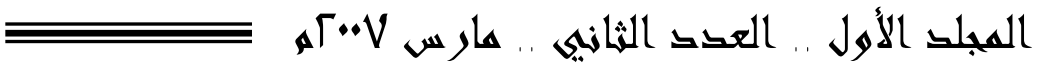

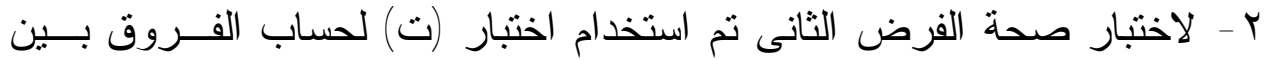
متوسطى المجمو عة الضابطة و المجموعة التجريبية فى الأداء البعدى على التى اختبار الذكاء الانفعالى كتقرير ذاتى ، ويوضـح جدول (ع ) تلك النتائج.

جدول ( ؛) : نتائج اختبار (ت) للفروق بين متوسطى درجات المجموعة التجريبية والمجموعة الضابطة فى الإي الأداء البعدى على اختبار الذكاء الافععالى كتقرير ذاتى لئى

\begin{tabular}{|c|c|c|c|c|c|c|c|c|c|}
\hline 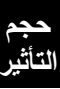 & هربتاع & مستوي الدالة & $ت$ & الحرجية & $\varepsilon$ & P & ن & الججموعة & البعد \\
\hline \multirow[b]{2}{*}{ كبير } & \multirow{2}{*}{. \&l } & \multirow{2}{*}{ مستوى دالة عند. } & \multirow{2}{*}{ V.ro } & \multirow{2}{*}{ VA } & ¿.AV & r.,. & $\varepsilon$. & الضابطة & \multirow{2}{*}{ الإفعالات } \\
\hline & & & & & $7.1 \%$ & $\leqslant 0 . \leqslant$. & $\varepsilon$. & التجريبية & \\
\hline \multirow{2}{*}{ كبير } & \multirow{2}{*}{.ro } & \multirow{2}{*}{ مستوى ل . .. } & \multirow{2}{*}{7.0.} & \multirow{2}{*}{$\mathrm{vA}$} & 7.11 & $r \cdot . r r$ & $\varepsilon$. & الضابطة & \multirow{2}{*}{ التعاطف } \\
\hline & & & & & 0.91 & rq. 7. & $\varepsilon$. & التجرييية & \\
\hline \multirow{2}{*}{ كبير } & \multirow{2}{*}{..$\varepsilon \varepsilon$} & \multirow{2}{*}{ مستوى لـ د. .. } & \multirow{2}{*}{ V.VT } & \multirow{2}{*}{ VA } & $\varepsilon .10$ & rq. 9. & $\varepsilon$. & الضابطة & \multirow{2}{*}{ الالفعالات } \\
\hline & & & & & T. TH & r9.7. & $\varepsilon$. & التجريبية & \\
\hline \multirow[b]{2}{*}{ كبير } & \multirow[b]{2}{*}{ זד. } & \multirow{2}{*}{ مستوى الـ ـ .. } & \multirow[b]{2}{*}{$11 . \varepsilon r$} & \multirow[b]{2}{*}{$\mathrm{vA}$} & T.TE & $Y \Sigma . \wedge V$ & $\varepsilon$. & الضابطة & \multirow{2}{*}{ الافعقالية } \\
\hline & & & & & T.1乏 & r..IA & $\varepsilon$. & التجريبية & \\
\hline \multirow{2}{*}{ كبير } & \multirow{2}{*}{$\cdot, Y Y$} & \multirow{2}{*}{ مستوى الـ ـ. . } & \multirow{2}{*}{ 纟.VT } & \multirow{2}{*}{$\mathrm{VA}$} & 7.10 & rr. 9 r & $\varepsilon$. & الضابطة & \multirow{2}{*}{ الاجتماعي اصل } \\
\hline & & & & & $\varepsilon . V T$ & YA.VT & $\varepsilon$. & التجرييية & \\
\hline \multirow[b]{2}{*}{ كبير } & \multirow{2}{*}{.01} & \multirow{2}{*}{ 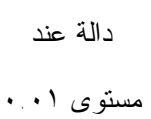 } & \multirow{2}{*}{$1 \cdot . r 1$} & \multirow{2}{*}{$\mathrm{vA}$} & $10.9 \pi$ & $1 \leq \varepsilon . r T$ & $\varepsilon$. & الضابطة & \multirow{2}{*}{ الكجىىع } \\
\hline & & & & & 19.71 & 110.0. & $\varepsilon$. & التجريبية & \\
\hline
\end{tabular}

ويتضح من الجدول السابق وجود فروق بين منوسطى المجموعـــة الضــــابطة

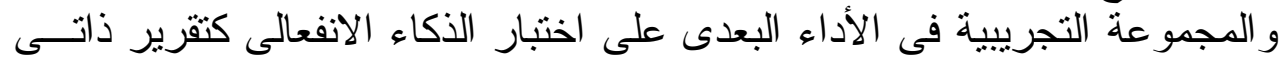

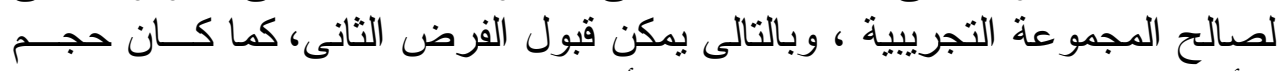

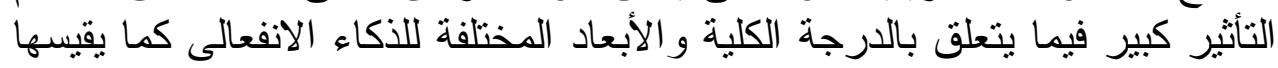

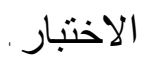

ب - لاختبار صحة الفرض الثالث تم استخدام اختبار (ت) لحساب الفروق بين

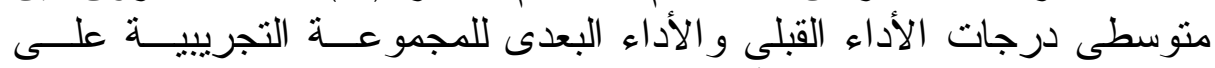

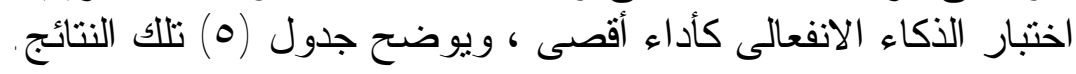

\section{IYY}

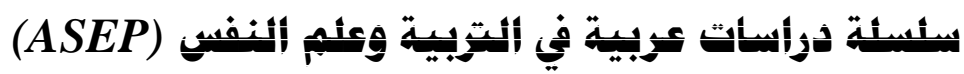




\begin{tabular}{|c|c|c|c|c|c|c|c|c|c|}
\hline التأثبِي & ريتا & مستوى الدلاية & $ت$ & لدرجية & $\varepsilon$ & p & ن & الألاء & البعد \\
\hline \multirow{2}{*}{ كبير } & \multirow{2}{*}{.10} & \multirow{2}{*}{ مستوى د الة عند. } & \multirow{2}{*}{ T.TE } & \multirow{2}{*}{ rq } & 1.79 & $1 \varepsilon .74$ & $\varepsilon$. & القبلي & ادارك \\
\hline & & & & & 1.9. & $10.7 r$ & $\varepsilon$. & البعدى & الاففعالات \\
\hline \multirow{2}{*}{ كبير } & \multirow{2}{*}{.10} & \multirow{2}{*}{ مستوى د الة عند. } & \multirow{2}{*}{ r. Tr } & \multirow{2}{*}{ rq } & $1 . \leqslant 0$ & $9 . V r$ & $\varepsilon$. & القبلى & تسهيل \\
\hline & & & & & $1 . r \wedge$ & $1 . .09$ & $\varepsilon$. & البعدى & التهكير \\
\hline \multirow{2}{*}{ كبير } & \multirow{2}{*}{ 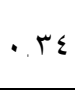 } & \multirow{2}{*}{ مستوى ال . .. } & \multirow{2}{*}{.01} & \multirow{2}{*}{ rq } & $1 . r \varepsilon$ & 11.09 & $\varepsilon$. & القبلى & فهم \\
\hline & & & & & 1.17 & $1 \leq .74$ & $\varepsilon$. & البعدى & الإفعالات \\
\hline \multirow{2}{*}{ كبير } & \multirow{2}{*}{$.1 \mathrm{~V}$} & \multirow{2}{*}{ مستوى د الة ع. .. } & \multirow{2}{*}{ r.Vq } & \multirow{2}{*}{ rq } & $1 . \cdot v$ & A. ro & $\varepsilon$. & القبلى & إلدارة \\
\hline & & & & & $\therefore \times 7$ & ᄉ. $\wedge 7$ & $\varepsilon$. & البعدى & الإفعالات \\
\hline \multirow{2}{*}{ كبير } & \multirow{2}{*}{. To } & \multirow{2}{*}{ مستوى 1 ـ. .. } & \multirow{2}{*}{.01} & \multirow{2}{*}{ rq } & r.v & $\{7, Y)$ & $\varepsilon$. & القبلى & المجموع \\
\hline & & & & & r.o. & $\{9 . \vee 1$ & $\varepsilon$. & البعدى & (الكلى \\
\hline
\end{tabular}

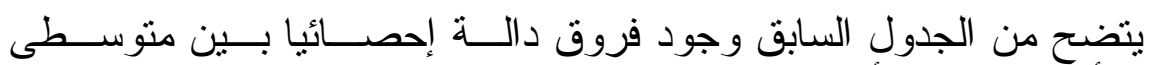

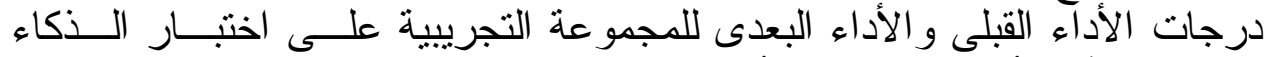

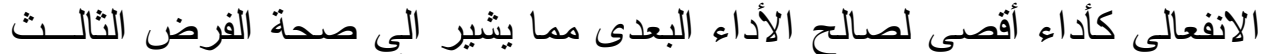

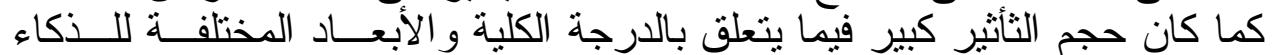
الانفعالى كما يقيسها الاختبار . كبير

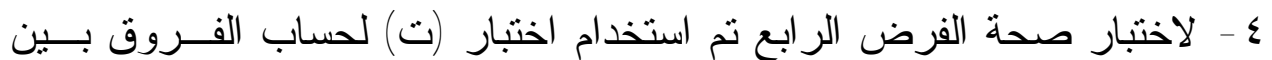

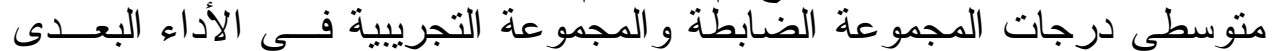

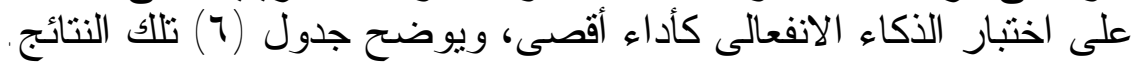
جدول (†) : نتائج اختبار (ت) للفروق بين متوسطى درجات المجموعة التجريبية والمجموعة الضابطة فى الإي

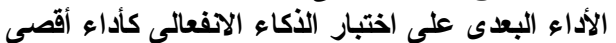

\begin{tabular}{|c|c|c|c|c|c|c|c|c|c|}
\hline التأثبر & هريت & مستوى الدلال & 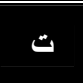 & الرجية & $\varepsilon$ & r & ن & المجموعة & البعد \\
\hline \multirow[b]{2}{*}{ صغير } & \multirow[b]{2}{*}{$\because .0$} & \multirow{2}{*}{ 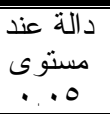 } & \multirow[b]{2}{*}{ r. $\cdot \Lambda$} & \multirow[b]{2}{*}{$\vee \wedge$} & $1.9 \varepsilon$ & $1 \varepsilon . V T$ & $\xi$. & الضابطة & \multirow{2}{*}{ الإفعالات } \\
\hline & & & & & 1.9. & $10.7 \mathrm{r}$ & $\varepsilon$. & التجريبية & \\
\hline \multirow[b]{2}{*}{ متوسط } & \multirow[b]{2}{*}{.11} & \multirow{2}{*}{ مستوى عند } & \multirow[b]{2}{*}{ r.17 } & \multirow[b]{2}{*}{$\vee \wedge$} & $1 . \varepsilon$. & 9.7. & $\varepsilon$. & الضابطة & \multirow{2}{*}{ تشهيل } \\
\hline & & & & & $1 . r \Lambda$ & $1 . .09$ & $\varepsilon$. & التجريبية & \\
\hline \multirow[b]{2}{*}{ كبير } & \multirow[b]{2}{*}{$.1 \leq$} & \multirow{2}{*}{ مستة عند } & \multirow[b]{2}{*}{$r .71$} & \multirow[b]{2}{*}{ VA } & 1.01 & 11.00 & $\varepsilon$. & الضابطة & \multirow{2}{*}{ الاهفعالات } \\
\hline & & & & & $1 . \cdot 7$ & $1 \leq .7 \pi$ & $\varepsilon$. & التجريبية & \\
\hline \multirow[b]{2}{*}{ متوسط } & \multirow[b]{2}{*}{.11} & \multirow{2}{*}{ دالة عند } & \multirow[b]{2}{*}{ r.l. } & \multirow[b]{2}{*}{$\vee \wedge$} & $.9 \varepsilon$ & $\Lambda . r V$ & $\varepsilon$. & الضابطة & \multirow{2}{*}{ الإفعالات } \\
\hline & & & & & $\because V 7$ & $\wedge . \wedge 7$ & $\varepsilon$. & التجرييية & \\
\hline \multirow[b]{2}{*}{ كبير } & \multirow[b]{2}{*}{ 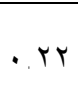 } & \multirow{2}{*}{ 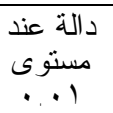 } & \multirow[b]{2}{*}{$\varepsilon . V}$. & \multirow[b]{2}{*}{ VA } & T. YV & $\leqslant 7.1 \leqslant$ & $\varepsilon$. & الضابطة & \multirow{2}{*}{ المجموع } \\
\hline & & & & & r.o. & $\{9, v)$ & $\varepsilon$. & التجريبية & \\
\hline
\end{tabular}

\section{AY}

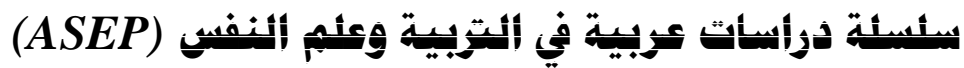


ב"

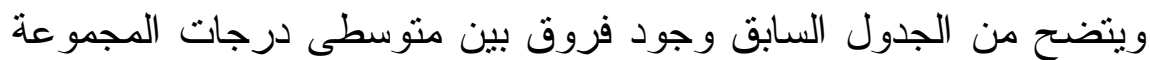

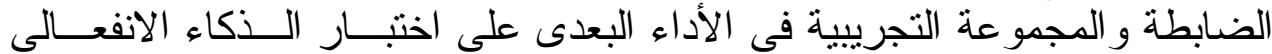

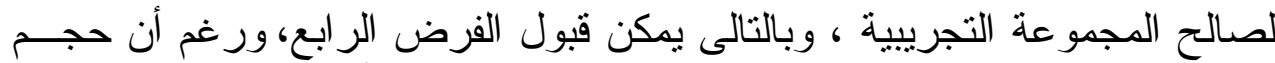

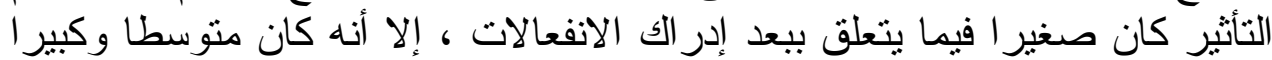

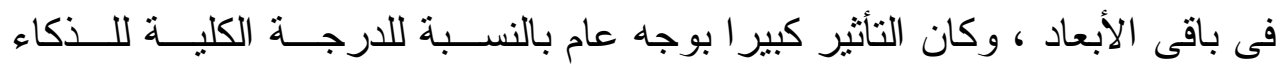

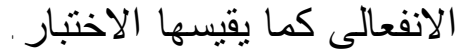

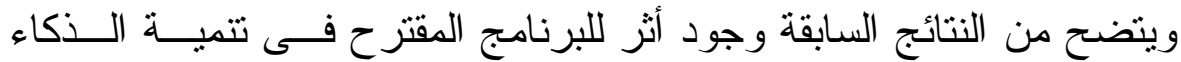

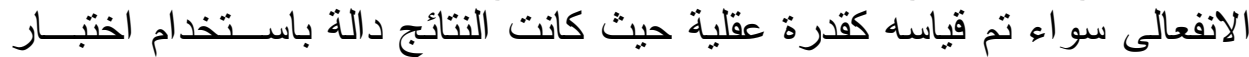
الأكاء الانفعالى كأداء أقصى (Mayer, et al.,2002b)، أو تم قياسه كمجمو عة كة

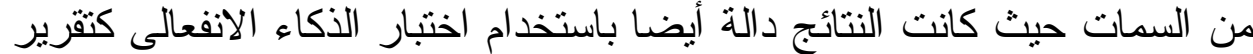

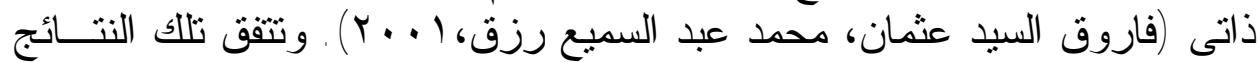

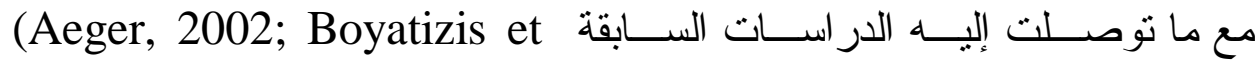
al,1995; Boyatzis et al, 1996; Boyatzis et al, in press; Bruno, et al., 2003; Clark. et al., 2003; Curtis, 2000; DuPont, 1998; Fischer, 2003; Gore,2002; Law, et al, 2004; Luskin et al., 2005; Richardson\& Evans, 1997)

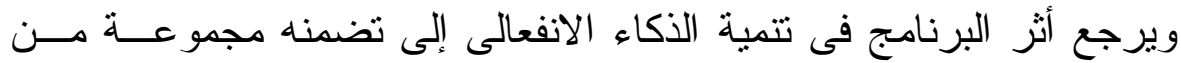

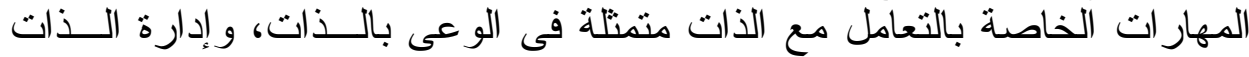

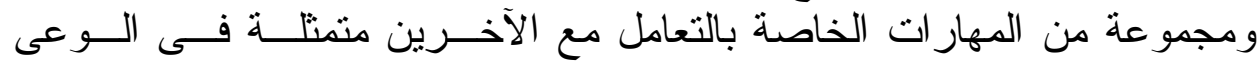

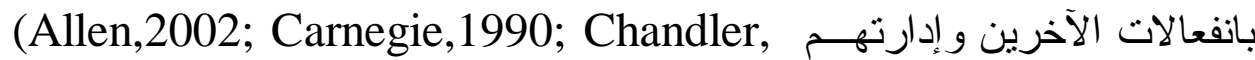

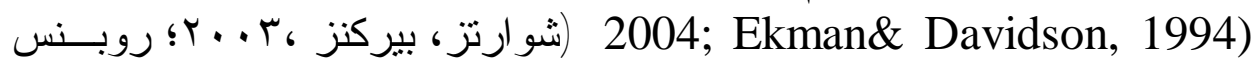

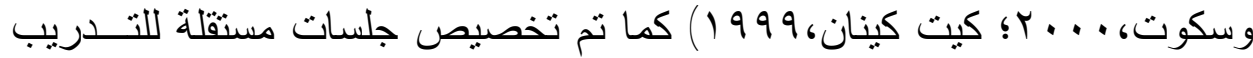

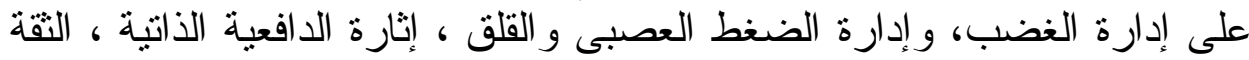

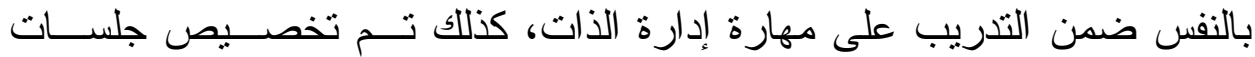

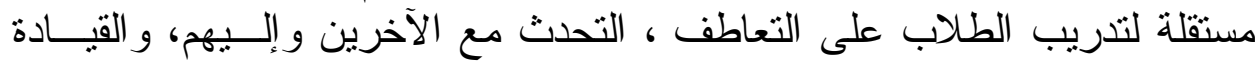
وصنع القرار . مان.

كما ترجع فاعلية البرنامج أيضا لما تضمنه من أنشطة تتعامل مــع الأبعـاد

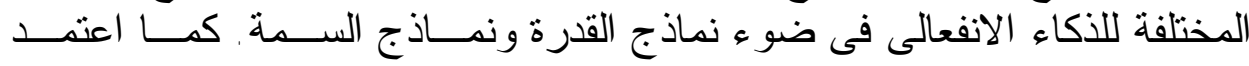

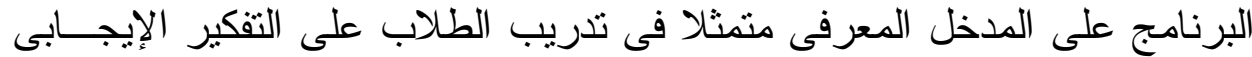

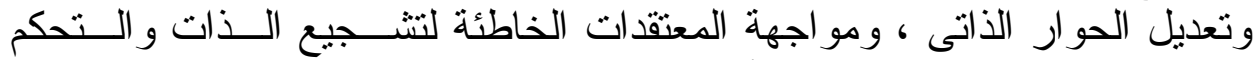
بالانفعالات السالبة ، كما اعتمد أيضا على المدخل السلوكى متمثنلا فى اســـتخدام 


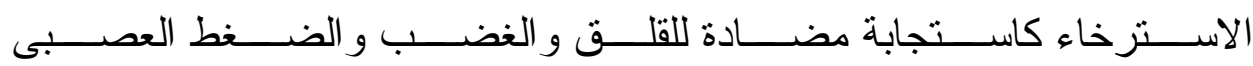

.(Madders, 1988; Trotter, 1999)

كذلك ترجع فاعلية البرنامج لما قدمه من تغذية راجعة للمتدربين طو ال فتــرة

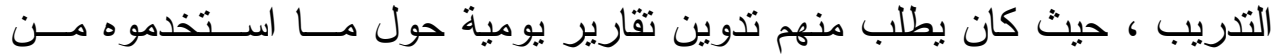

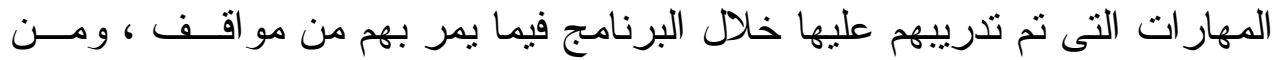

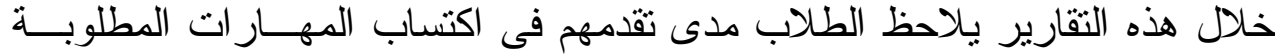

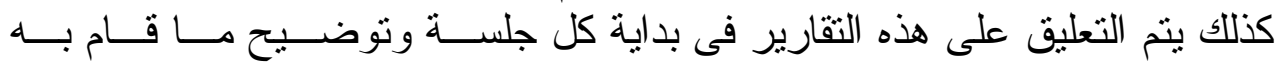

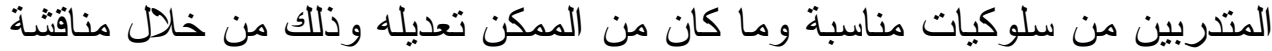

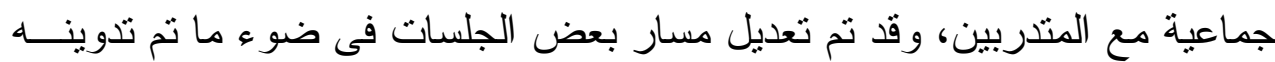

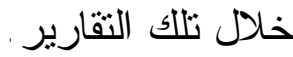

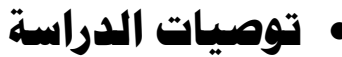

من خلال النتائج السابقة توصى الدر اسة بما يلى

1 - تدريب الطلاب على مهارة الوعى بالذات ضمن بر امج نتمية الذكاء الانفعالى

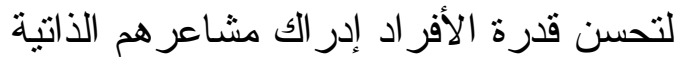

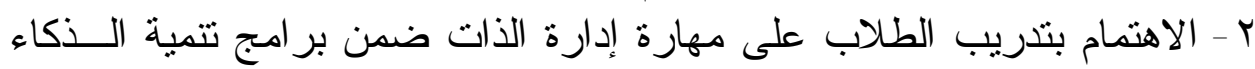

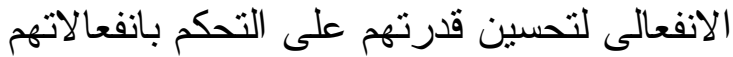

ץ - تدريب الطلاب على إدارة الغضب ضمن مهار ات إدارة الذات

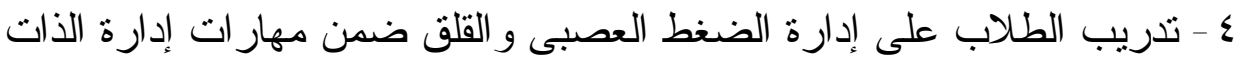

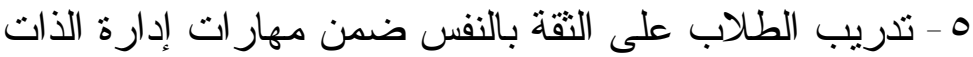

7 - تدريب الطلاب على تشجيع الذات و إثارة الدافعية الذاتية ضمن مهار ات إداب إدارة

V - الاهتمام بتدريب الطلاب على التفكير الايجابى ضمن مهــار ات إدارة الــذات للسيطرة على المشاعر السلبية

ᄉ - ثقديم تدريبات خاصة بالاسترخاء للتخلب علـى حــالات الغضــب و القلــق

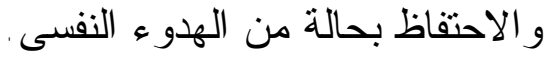

9 - تدريب الطلاب على قر اعة لغة الجسد ضمن مهارة إدر الك مشّاعر الآخرين • 1 - تدريب الطلاب التعاطف ضمن مهارة إدارة الآخرين 11 - تدريب الطلاب التحدث للآخرين ضمن مهارة إدارة الآخرين r ا - تدريب الطلاب على القيادة وصنع القرار ضمن مهارة إدارة الآخرين 


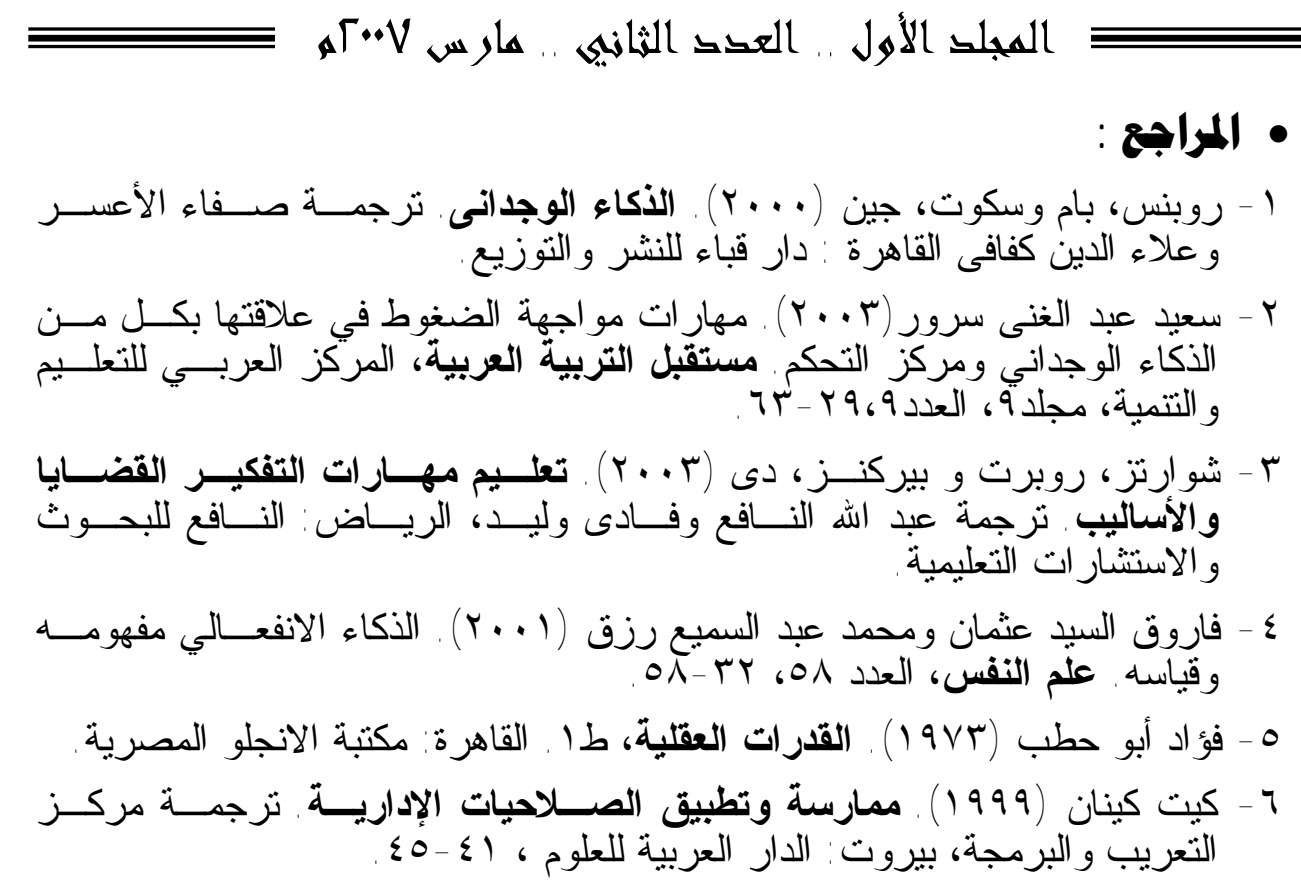

7- Aeger, A.(2002). Job Competencies and the Curriculum: An Inquiry into Emotional Intelligence in Graduate Professional Education." Unpublished paper. Raleigh: North Carolina State University. ERIC (ED465341)

8- Allen, D.(2002). Getting things done: The art of stress-free productivity. Londone: Piatkus Books.

9- Austin, E., Evans, P., Goldwater, R., Potter, V.(2005). A preliminary study of emotional intelligence, empathy and exam performance in first year medical students. Personality and Individual Differences, 39,1395-1405.

10- Bardach,R.(2008). Leading schools with emotional intelligence: a study of the degree of association between middle school principal emotional intelligence and school success. Capella University.

11- Bar-On, R.\& Parker,J. (2000). BarOn Emotional Quotient Inventory: Youth Version (BarOn EQ-I:YV): Technical Manual. Toronto, Multi-Health Systems.

12- Bastian, V.,Burns, N., Nettelbeck, T.(2005). Emotional intelligence predicts life skills, but not as well as personality and cognitive abilities. Personality and Individual Differences, $39,1135-1145$.

\section{$1 Y 7$}




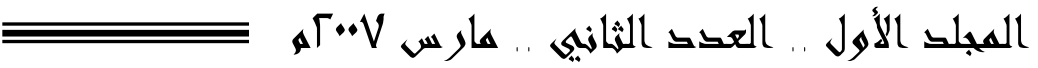

13- Boyatzis, R., Baker, A., Leonard, D.,Rhee, K.\& Thompson, L.(1995). Will it make a differences? Assessing a value-based, outcome oriented, competency-based professional program. In Boyatzis, R., Cowen, S., and Kolb, D.(Eds.) Innovating in professional education: Steps on a journey from teaching to learning. San Francisco: Jossey-Bass.

14- Boyatzis, R., Leonard, D., Rhee, K.\& Wheeler, J.(1996). Competencies can be developed, but not the way we thought. Capability, 2,2,25-41.

15- Boyatzis, R., Wheeler, J.\&Wright (in press). Competency development in graduate education: A longitudinal perspective.Proceeding of the First World Conference on SelfDirected Learning, GIRAT, Montreal.

16- Brown, R.\& Schutte, N.(2006). Direct and indirect relationship between emotional intelligence and subjective fatigue in university students. Journal of Psychosomatic Research, 60, 585-593.

17- Bruno, K., England, E. \&Chambliss, C.(2002).Social and emotional learning programs for elementary school students: Apilot Study. Emotional Intelligence Publication (ED463097)

18- Carnegie D. (1990). How to stop worrying and start living. London: Vermilion.

19- Chandler,S.(2004). 100 Way to motivate yourself: change your life forever. New Jersey: Career Press.

20- Cherniss,C.(2000).Social and Emotional competence in the work-place. The hand book of emotional intelligence. San Francisco: Jossey-Bass,433-458.

21- Cherniss, C.(2005).The business case for emotional intelligence. www.eiconsortium.org.

22- Clark.S.,Callister,R.,Wallace,R.(2003). Undergraduate management skills courses and students' emotional intelligence. Journal of Management Education, 27 ,1, 3-23 .

23- Curtis, L.(2000). Assessing the attainment of guidance outcomes related to the development of emotional intelligence skills and improved self concept. DAI,60(8A), 2812.

24- Day, A.\& Carroll, S.(2004) Using an ability-based measure of emotional intelligence to predict individual performance, group performance, and group citizenship behaviours. Personality and Individual Differences,36,1443-1458. 


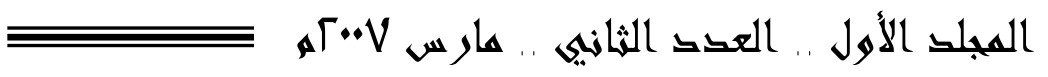

25- DuPont, N.(1998). Update on Emotional Competency: Helping to Prepare our Youth to Become Effective Adults. Rode Island State Department of Mental Health, Retardation and HospitalsCranston.(ED437 592)

26- Dwyer, B.(2001).Successful Training Strategies for the Twentyfirst Century: Using Recent Research on Learning to Provide Effective Training Strategies. International Journal of Educational Management, 15,6,312-318.

27- Ekman, P.\&Davidson, R. (1994). Fundamental questions about emotions. New York: Oxford University Press.

28- Engelberg, E.\& Sjoberg, L.(2004). Emotional intelligence, affect intensity, and social adjustment. Personality and Individual Differences, 37,533-542.

29- Fanning, B.(2002). The contributions of emotional intelligence to academic achievement and population.DAI,62(12A), 4055.

30- Fischer, R.(2003). The development, testing and evaluation of an emotional intelligence curriculum, Journal of adult evaluation, 32,1,7-17.(EJ665622)

31- Gardner,H. (1983). Frames of mind: the theory of multiple intelligences. New York: Basic Books.

32- Goleman, D.,(1995). Emotional intelligence. New York: Bantam Books.

33- Goleman, D., Boyatzis, R.\& Mckee, A.(2002). Primal Leadership: Realizing the power of emotional intelligence, Harvard Business School press.

34- Gore, S.(2002). Emotional intelligence and social adeptness ,interpersonal competence: middle school students Social Cognition. U.S.: Illinois.

35- Guilford, J.(1967). The nature of human intelligence. New York: McGraw Hill.

36- Hunt, N.\&Evans,D. (2003). Predicting traumatic stress using emotional intelligence. Behaviour Research and Therapy, 42,791-798.

37- Jaeger, A.(2003). Job competence and the curriculum: an inquiry into emotional intelligence in graduate professional education. Research in High Education,44,615-639.

38- Jordan, P., Ashkanasy, N., Hartel, C., Hooper, G.(2002). Workgroup emotional intelligence Scale development and 


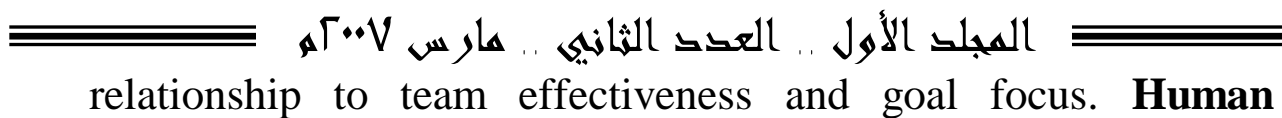
Resource Management Review,12, 195-214.

39- Kapp, C.(2000). Emotional intelligence (EQ) and success in post-graduate studies: a pilot study. South African Journal of Higher Education, 14,3,151-160.

40- Kellett, J., Humphrey, R.\& Sleeth, R.(2006). Empathy and the emergence of task and relations leaders. The Leadership Quarterly, 17, 2, 146-162.

41- Lane, R.\& Schwartz, G.(1987). Level of emotional awareness: A cognitive-development theory and its application to psychology. American Journal of Psychology, 144, 133-143.

42- Lapidus, L.(1998).Integrative research and integrative facilitate child and family development, education, readiness for head start and family self-sufficiency. ERIC, ED424001.

43- Law, G., Lomax,A., Jackson,M.\& Nelson,D.(2004). Emotional intelligence : a new student development model. A Paper Presented at the National Conference of the American College Personnel Association. Philadelphia, Pennsylvania.

44- Leible, T.\& Snell, W.(2004). Borderline personality disorder and multiple aspects of emotional intelligence. Personality and Individual Differences, 37, 393-404.

45- Luskin, F.;Aberman, R.\& Delorenzo, A.(2005). The training of competence in financial advisors. Issues in Emotional Intelligence, 1,2, 1-5

46- Lyons, J., Schneider,T.(2005). The influence of emotional intelligence on performance. Personality and Individual Differences, 39,693-703.

47- Madders,J.(1988). Stress and relaxation: self help techniques for every one. London: Macdonald Optima.

48- Matthews,G., Roberts,R\&Zeidner,M.(2003). Development of emotional intelligence: A skeptical- but not dismissiveperspective. Human Development, 46,109-114.

49- Mayer,J.\& Cobb,C. (2000). Emotional policy on emotional intelligence: Does it make sense? Educational Psychology Review, 12,163-183.

50- Mayer,J.\&Salovey,P.(1997).The intelligence of emotional intelligence. Intelligence, $17,4,433-442$.

\section{1 rq}

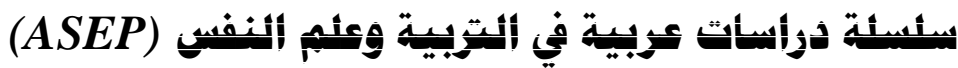




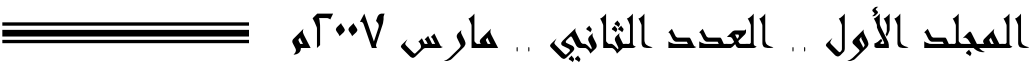

51- Mayer,J., Salovey, P. \& Caruso, D.(2000). Emotional intelligence meets traditional standards for an intelligence. Intelligence, 27,4,267-298.

52- Mayer, J., Salovey, P., Caruso, D.(2002a). Mayer-SaloveyCaruso Emotional intelligence test (MSCEIT) user's manual. New York: Multi-Health Systems Inc.

53- Mayer, J., Salovey, P., Caruso, D.(2002b). Mayer-SaloveyCaruso Emotional intelligence test (MSCEIT) Items Booklet. New York: Multi-Health Systems Inc.

54- McClelland, D.(1999). Identifying competencies with behavioral-event interview. Psychological Science, 9,5,331-339.

55- Palmer,B., Donaldson, C. \& Stough,C.(2002) Emotional intelligence and life satisfaction. Personality and Individual Differences, 33,1091-1100.

56- Parker, J. ,Creque,R., Barnhart,D., Harris, J., Majeski, S., Wood, L., Bond, J., Hogan, M. \& (2004a). Academic achievement in high school: does emotional intelligence matter. Personality and individual Differences, 37,1321-1330.

57- Parker, J. ,Summerfeldt, L., Hogan, M. \&Majeski, S.(2004b). Emotional intelligence and academic success: examining the transition from high school to university. Personality and individual Differences, 36,163-172.

58- Petrides, K.\&Furnham,A.(2000). On the dimensional structure of emotional intelligence. Personality and Individual Differences, 29,313-320.

59- Petrides, K.\& Furnham,A.(2001). Trait emotional intelligence: psychometric investigation with reference to established trait taxonomies. European Journal of Personality, 15,425-448.

60- Petrides, K., Frederickson, N.\& Furnham, A.(2004). The role of trait emotional intelligence in academic performance and deviant behavior at school. Personality and Individual Differences, 36,277-293.

61- Richardson, R,\& Evans,E.(1997). Social and Emotional Competence: Motivating Cultural Responsive Education. Paper presented at the annual conference and exhibit of the association for supervision and curriculum development. $52^{\text {nd }}$ Baltimore, MD, March 22-25

62- Salovey, P.\& Mayer, J.(1990). Emotional intelligence. Imagination, Cognition and Personality, 9,185-211. 


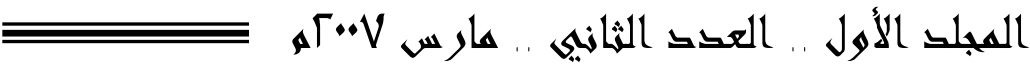

63- Schutte, N., Malouff, J., Hall, L., Haggerty, D., Cooper, J., Golden, c. (1998). Development and validity of a measure of emotional intelligence. Personality and Individual Differences, 25,167-177.

64- Seligman, M. (1990). Learned optimism. New York: Knopf.

65- Short, D.(2001). Analyzing Training from an Emotions Perspective. In Emotional and Behavior in the Workplace, Symposium 28.Academy of Human Resource Development (AHRD) Proceedings, Tulsa, OK, February 28-March4,edited by O.A. Aliaga. Baton Rouge, LA: Academy of Human Resource Development.(ED453 437).

66- Sy, T., Tram, S., O'Hara, L.(2005). Relation of employee and manager emotional intelligence to job satisfaction and performance. www. Sciencedirect.com

67- Taylor, E.(1996). Rationality and Emotional in Transformative Learning Theory: A Neurobiological Perspective. $37^{\text {th }}$ Adult Education Research Conference Proceedings, University of South Florida(ED 419087).

68- Thorndike.E.,(1920). Intelligence and its uses. Harpers's Magazine. 140,227-235.

69- Trinidad, D.\& Johnson, C.(2002). The association between emotional intelligence and early adolescent tobacco and alcohol use. Personality and Individual Differences. 32,95-105.

70- Trotter,J.(1999). Coping with stress ,stress education curriculum, a stress control program for troubled youth $\left(5^{\text {th }}\right.$.ed). Atlanta, Wholistic Stress Control Institute, Inc, ERIC, ED423357.

71- Weiss, R.(2000). Emotional and Learning . Training and Development, 54,11, 44-48.

72- Wong,C., Foo, M., Wang, C.,Wong,P.(2006). The feasibility of training and development of EI: An exploratory study in Singapore, Hong Kong and Taiwan. (article in press), www. Sciencedirect.com

73- Wong, C.\& Law, K. (2002). The effects of leader and follower emotional intelligence on performance and attitude : An exploratory study. The Leadership Quarterly, 13,3,243-274.

74- Zeidner, M., Robert, R.\& Matthews, G.(2002). Can emotional intelligence be schooled? A critical review. Educational Psychologist,37,215-231. 